\title{
HIV-1 Assembly, Release and Maturation
}

\author{
Laurence Briant ${ }^{*}$, Bernard Gay, Christian Devaux, Nathalie Chazal
}

Centre d'Études d'Agents Pathogènes et Biotechnologies pour la Santé (CPBS), UMR5236 CNRS, Université Montpellier 1-Montpellier 2, Montpellier, France.

E-mail: $\{$ laurence.briant, bernard.gay, christian.devaux, nathalie.chazal $\} @$ cpbs.cnrs.fr

Received July 29, 2011 ; revised September $29^{\text {th }}, 2011$; accepted October $11^{\text {th }}, 2011$.

\begin{abstract}
Late steps of HIV-1 life cycle are determinant for optimal dissemination of the virus to new target cells. These steps include assembly of structural precursors, budding of the new particle and maturation into fully infectious virions. Each step is finely tuned and timely regulated to allow the appropriate assembly of structural components, the efficient recruitment of viral and cell partners and the timely regulated proteolytic processing of the protein precursors. Despite the huge number of studies devoted to the definition of molecular mechanisms regulating these steps, a number of question remains to be answered before they are clearly apprehended. The elucidation of the role played by each viral proteins, nucleic acids as well as host-encoded factors will provide new clues in the understanding of the retroviral assembly/maturation process and will allow further development of new antiviral compounds. This review reports the most recent progress as well as the questions that remain to be answered in the field of HIV-1 assembly, release and maturation. Finally, we also describe the data available on the design and use of new antiretroviral drugs targeting these specific steps of the retroviral replication.
\end{abstract}

Keywords: HIV-1, Assembly, Maturation, Release, Gag, Antiviral Molecule

\section{Introduction}

HIV-1 assembly, release and maturation are steps of primary importance for the production of infectious particles capable to disseminate in new target cells. Notably, the capacity of HIV-1 to produce fully mature proteins addressed to appropriate cellular compartments, the competence of these viral proteins to multimerize and to interact with viral nucleic acids and the faculty of these complexes to recruit cellular partners required for efficient release in the extracellular space is of crucial importance for viral dissemination. Even they have attracted a considerable effort since the discovery of HIV-1, the mechanisms involved in the assembly of infectious particles remain incompletely defined. The understanding of protein-protein and protein-nucleic acids contacts as well as interactions with cellular lipids engaged during retroviral assembly more than ever represents a major challenge for the future development of new HIV-1 inhibitors.

\section{The Viral Partners of HIV-1 Assembly}

HIV-1 gene transcription generates a $9 \mathrm{~kb}$ RNA that has three fates: firstly, multisplicing that gives rise to regulatory proteins (Tat, Rev, Nef, Vpr, Vif); secondly, singly spliced RNAs that support translation of envelope glycoproteins (Env). The third species is an unspliced RNA that both serves as a matrix for the translation of Gag structural polyprotein and of a GagPol precursor supporting viral enzyme production and that forms a dimer of genomic RNA encapsidated into newly assembled virions. The infectious HIV-1 particle is a spherical particle of 120 - $150 \mathrm{~nm}$ surrounded by a lipid bilayer derived from the host cell plasma membrane in which is inserted the viral envelope composed of the gp41 transmembrane protein non covalently attached to the gp 120 surface glycoprotein. The viral envelope is linked to a spherical shell composed by the matrix (MA) protein. In the center of the mature particle, a cone shaped core resulting from assembly of the mature capsid protein (CA) contains a dimeric viral genomic RNA associated with the nucleocapsid protein (NC). The annealing of a tRNA $^{\text {lys3 }}$ to the primer binding site (PBS) in genomic RNA is required for viral infectivity. In addition, the conical capsid contains Vpr, Nef, Vif accessory proteins and the viral enzymes integrase and reverse transcriptase. Finally, a huge variety of membrane or cytosolic proteins and RNA derived from the host cell are incorporated into HIV-1 particles [1]. 


\section{A Molecular Model of Gag Assembly}

The production and release of an infectious HIV-1 particle is orchestrated by the Gag polyprotein precursor which is the major component of HIV-1 assembly. Indeed, Gag polyprotein is sufficient for in vitro assembly and in vivo production of virus-like particles (VLPs) [2]. Such particles contain approximately 5000 Gag molecules [3]. Interaction of Gag with cellular membranes and the endocytic machinery, oligomerization at the assembly site, contacts between Gag and viral proteins and nucleic acids and finally, maturation of Gag are determinant for the production of fully infectious particles. Gag polyprotein is comprised of four major structural domains: p17 matrix (MA), p24 capsid (CA), p7 nucleocapsid (NC), p6 spaced by two linker peptides SP1 and SP2 (Figure 1). When addressed at the plasma membrane, Gag polyproteins are radially organized with the MA domain tightly associated with the inner face of the lipid bilayer, while the C-terminus is oriented towards the center of the nascent particle, $[4,5]$. Gag molecules assemble into a fullerene-like model with threefold symmetry and form a hexagonal network of rings that can be visualized as patches of electron dense material beneath the cell membrane in electron microscopy imaging $[3,6]$. Multiple cooperative contacts between adjacent Gag polyproteins, lipids or nucleic acids allow the formation of an organized lattice that determines the capacity to produce an assembled viral particle. The function of each domain of Gag during the assembly process has been decrypted.

\subsection{Role of the MA Domain in HIV-1 Assembly}

MA is the membrane proximal domain of the Gag polyprotein. Its function, as a domain of Gag or as a mature structural protein, relates particularly to the trafficking of HIV-1 complexes, membrane binding and Env incorporation. The structure of HIV-1 MA has been solved by crystallography and NMR [2]. The first 104 residues of MA form a globular domain composed of four $\alpha$ helices centrally organized and a fifth one which is projected away from the packed bundle of helices. This globular core is capped by a three-stranded $\beta$ sheet-enriched in basic residues. When expressed in mammalian cells, MA is found both in association with cellular membranes and in a membrane-free form. Regarding the unprocessed Gag precursor, despite detected in the cytoplasm as monomers and low-order multimers, it is almost exclusively bound to membranes where it forms patches of assembled multimers [7]. The presence of a myristic acid at the $\mathrm{N}$-terminal end of MA was established as the primary determinant for interaction of Gag with acid phospholipids $[2,8]$. According to the local concentration of Gag, the conformation of the MA domain is switched from a state where the myristate moiety is sequestrated inside the core of the protein to a myristate-exposed conformation. When exposed, this myristate moiety is capable to insert into membrane bilayers and together with a stretch of basic residues spanning positions 26 - 32 in MA dictates the capacity of MA the protein to interact with cellular membranes [8]. This basic domain engages electrostatic interactions with the negatively charged headgroups of acidic phospholipids in the inner leaflet of the plasma membrane.

The nature of microdomains supporting the interaction of Gag with cellular membranes is discussed below. Then, the MA domain organizes in a hexameric network of trimers $[9,10]$. The formation of the trimer unit is dictated by weak interactions of $\alpha$-helix 4 [2,11]. However, minimal Gag constructs lacking matrix domain retain the capacity to assemble and to generate efficient particle formation when the matrix domain is substituted by a myristylation signal [2]. Accordingly, MA, despite playing a structural role in HIV-1 assembly cannot be considered as a driving force in viral particle formation.

Besides its function in lipid binding, MA is also required for incorporation of gp120 and gp41 envelope glycoproteins into nascent particles [2,12]. A considerable number of studies reported that MA interacts with the intracytoplasmic domain of gp41 during assembly and proposed that these interactions, either occurring directly or through a molecular bridge involving a cell cofactor, promote the recruitment of Env complexes into nascent virions (for review see [12]). Finally, in addition to these activities, several studies have reported the capacity of the retroviral MA to bind nucleic acids (reviewed in [13]). The RNA binding site in MA was mapped to overlap PI(4,5)P2 interacting domain. Deletion of this sequence allows production of poorly infectious viruses that can be rescued in trans by coassembly with wild type Gag proteins [14]. Recently, inositol phosphate binding was reported to stimulate nucleic acids chaperone activity of Gag [15]. In contradiction with this observation, RNase treatment of Gag in vitro translation lysates reduces the selectivity of Gag binding to $\mathrm{PI}(4,5) \mathrm{P} 2$ liposomes. In this model, MA interaction with nucleic acids is likely to increase the selectivity of MA for PI(4,5)P2 rich cellular membranes and to prevent premature intracellular assembly. However, cryoEM study revealed that Gag in solution undergoes a conformational switch according to interaction with RNA or lipids. The low affinity of MA domain-RNA binding is proposed to be reversed by MA-lipid interaction, allowing the conversion from a compact RNAbound Gag protein to an extended lipid-bound Gag [16]. The exact contribution of such observations needs to be 
explored. In conclusion, MA not only acts as a scaffold that brings together Env, Gag and nucleic acids during assembly but also regulates targeting of Gag to the cell membranes.

\subsection{Contacts in the CA Domain of Gag}

The CA domain in Gag is strictly required for assembly. The CA domain present in immature virions is organized as a hexagonal lattice with a characteristic spacing averaging $8 \mathrm{~nm}$ [17]. After protease processing, the mature CA protein is released as a 231 amino acids polypeptide that folds into two distinct globular domains connected by a flexible linker structured as a $3_{10}$ helix $[18,19]$. According to crystal structures and cryo-electron microscopy reconstructions, CA still forms a network of hexameric rings and of pentamers in the fullerene core [20,21]. The CTD moiety of CA and the adjacent SP1 domain are required for Gag multimerization. Three separate functional domains have been identified (reviewed in [22]): 1) CA helix 9 in the CTD moiety directs the formation of Gag dimers in solution and in crystals through parallel packing; 2) The Major Homology Region (MHR) represents a stretch of 20 residues (amino acid 153 to 172 in CA) highly conserved in capsid proteins from distinct retroviruses and strictly required for HIV-1 assembly. Swapping of the MHR regions of adjacent Gag molecules was proposed to be directly involved in $\mathrm{CA}_{\text {СTD }}$ dimerization and in stabilization of the hexameric network [23]; 3) The NTD moiety of CA, more precisely $\alpha$ helices 1 and 2, and helices 4 and 7 stabilize the immature lattice by six-fold symmetric interactions between neighboring hexamers. However, the $\mathrm{CA}_{\mathrm{NTD}}$ is not strictly required for Gag assembly as mutagenesis of this domain allows VLPs production. This region also contains an exposed proline-rich loop required for the recruitment to the viral particle of the host cell encoded peptidyl-prolyl-isomerase cyclophilin A (CypA) [24]. Despite dispensable for assembly, CypA incorporation determines HIV-1 infectivity [24,25] and plays a key role both in viral uncoating during early steps of infection [26] and in recognition of the incoming capsids by cellular restriction factors including TRIM5 $\alpha$ [27,28]. Accordingly, assembly of the Gag precursor is primarily determined by $\mathrm{CA}_{\mathrm{CTD}}$ while the $\mathrm{N}$-terminal domain rather contributes to assembly of mature CA.

\subsection{Flexible Linkers in HIV-1 Assembly}

Gag precursor is additionally characterized by the presence of flexible junctions, a common feature of retroviral Gag proteins [29]. Junctions located at the CA/NC and NC/p6 interface are termed SP1 and SP2 linkers respectively (Figure 1). Structure prediction as well as NMR study of a Gag fragment containing $\mathrm{CA}_{\mathrm{CTD}}$, SP1 and $\mathrm{NC}$ revealed that the flanking linker domain in both $\mathrm{CA}$ and $\mathrm{NC}$ are flexible and that the first 7 amino acids in SP1 fold into an $\alpha$-helix [30]. SP1 structuration is highly influenced by the environment [31]. Upon assembly, this domain folds into a six helix bundle as observed by elec-

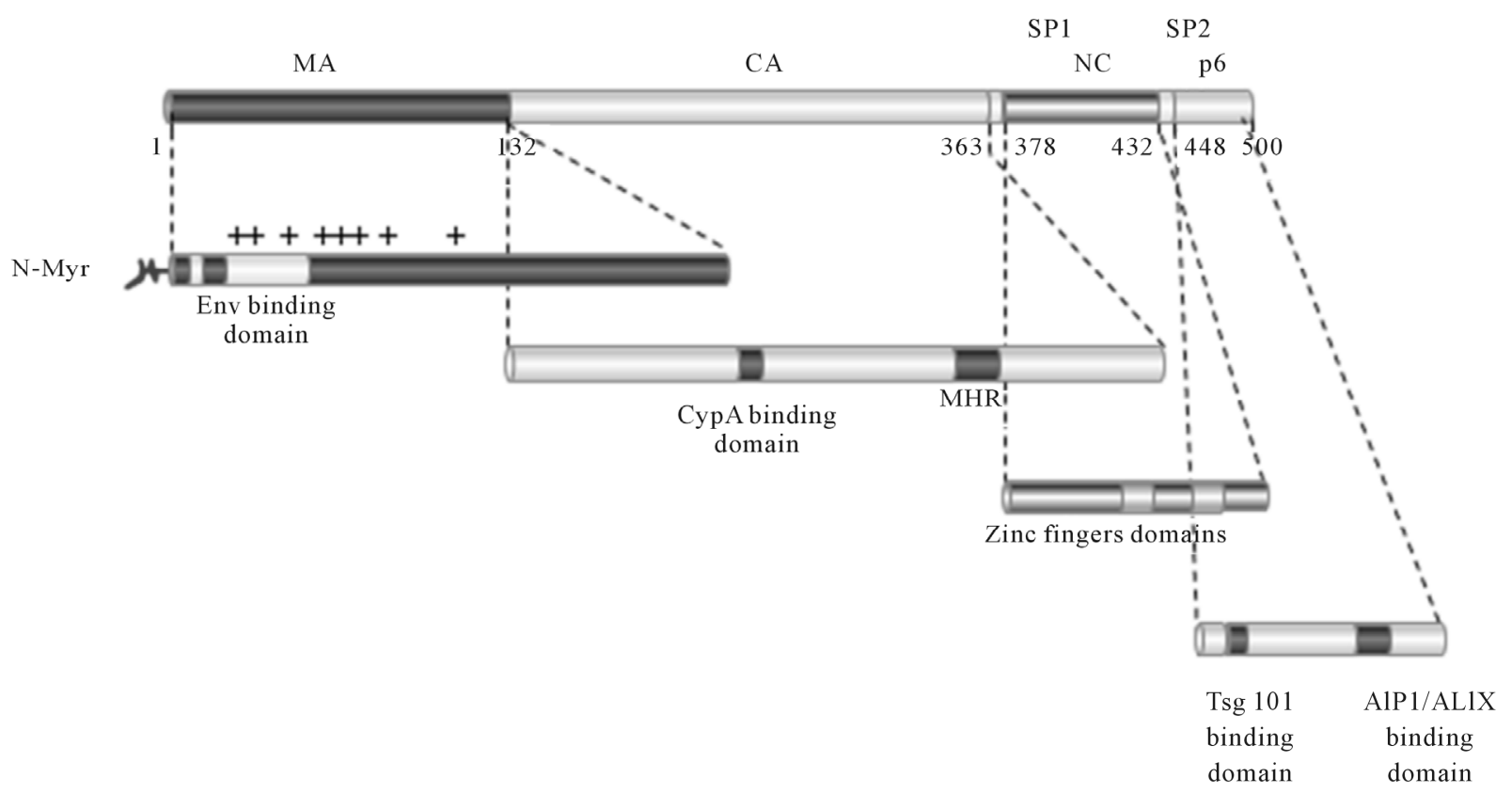

Figure 1. Organization of Gag polyprotein and functional domains of mature proteins. +: positively charged amino acids; N-Myr: Myristate; MA: matrix; CA: capsid; SP1: spacer peptide 1; NC: nucleocapsid; SP2: spacer peptide 2; Env: envelope; CypA: cyclophilin A; MHR: Major Homology Region. 
tron cryotomography [32]. This property was related to changes in SP1 conformation dictated by modifications in the local concentration of Gag molecules [31]. Such properties are of crucial importance for HIV-1 assembly. Indeed, SP1 plays a major role in Gag multimerization, higher order organization of the Gag lattice and VLP assembly $[30,31,33,34]$. Mutations of the CA-SP1 region, especially modification of the first 6 residues in SP1, prevent viral particle to assemble properly and reduce the strength of Gag-Gag interactions underlying particle formation [31]. Moreover, deletion of SP1 converts the spherical particles assembled in vitro into conical particles reminiscent of mature capsids. Accordingly, SP1 was proposed to act as a molecular switch [30]. The structural model currently proposed for SP1 in HIV-1 assembly supports that oligomerization of the C-terminal region of Gag would trigger a signal transmitted from the C-terminal region of Gag toward the CA domain, allowing conformational changes in SP1 structure. Such modifications would result in the exposure at the external part of the complexes of assembly interfaces in the CA and SP1 domains which are otherwise cryptic. Nevertheless, it has to be kept in mind that this significant function of HIV-1 spacer peptides in particle assembly is transient as the proteolytic cleavage of SP1 linker is a prerequisite to turn the non infectious particle into an infectious virus.

While most attention was devoted to the study of SP1 function, similar conclusions can be drawn for SP2 linker located between $\mathrm{NC}$ and $\mathrm{p} 6$ domains of Gag. Indeed, proper cleavage between p6 and SP2 is critical for the formation of fully infectious particles. Mutations inhibiting SP2-p6 processing result in the assembly of virions with aberrant cores that are unable to replicate in $\mathrm{T}$ cells [35]. Recently, the cleavage at the SP2-p6 site was reported to be necessary for efficient genome integration by the infecting virus [36]. Inhibition of the NC-SP2 maturation by mutations of the two proline residues in the middle of SP2, that confer conformational constraints to this linker, also abolished viral replication despite the uncleaved NC-SP2 protein has been found to be more efficient than mature $\mathrm{NC}$ at promoting RT-associated functions in vitro [37]. Persistence of NC-SP2 protein reduces genomic RNA dimer stability. Recently, the appropriate maturation of the NC-SP2-p6 precursor has been shown to be required for formation of a stable RNA dimer within the HIV-1 particle [38]. According to this model, the RNA dimer stabilization begins during the primary cleavage SP1-NC of Gag and reaches stable and uniform state allowing infectivity, once Gag processing is complete. Altogether these observations highlight that attention must be payed to the role of SP2 flexible linker and uncleaved NC-SP2 proteins in assembly of fully infectious HIV particles.

\subsection{Nucleocapsid and Packaging of Viral RNA}

The C-terminal part of Gag is central in the assembling particle and links the retroviral RNA genome at the level of the NC domain. $\mathrm{NC}$ is composed of two highly conserved zinc fingers of the CCHC form organized in tandem. Chelating of $\mathrm{Zn}^{2+}$ folds the central domain of the protein while the $\mathrm{N}$ - and $\mathrm{C}$-terminal moieties remain essentially unfolded. Substitution of the $\mathrm{CCHC}$ residues, that modify the globular folding of NC, modifies Gag trafficking in the producer cell, alters the virion core structure and causes a complete loss of infectivity (for revue see [39] and [13]). The role of NC in HIV-1 assembly is multiple. Primarily, its function relies on the capacity of the zinc-finger domains to interact with the genomic RNA and to direct the packaging of the viral genome into the nascent particle. Both of them, with a prominent role for the N-terminal zinc-finger structure, are critical for the selection of the viral genomic RNA and the assembly of the virion core [40]. At the level of the HIV-1 full length RNA, a hundred nucleotides located in $5^{\prime}$ of the untranslated region (UTR) and in 5' of the gag gene form the $\psi$ encapsidation sequence gene (for revue see [13]). This motif interacts with exposed bases of the RNA loop in the packaging site of genomic RNA while the C-terminal zinc finger motif is only partly involved in NC/RNA interaction. Additional contacts with basic residues flanking the zinc fingers along the SP1 linker are also required for HIV-1 genome packaging. Interestingly, Gag containing a leucine zipper in place of NC domain assembles efficiently [30,41]. Therefore, the RNA binding property of NC has been proposed to promote Gag concentration and organization at the budding site, the RNA genome playing the role of a scaffold in Gag lattice formation. Despite NC displays a strong preference for HIV-1 genomic RNA, contacts of the zing-fingers with non specific cellular RNAs or DNAs can also occur and promote Gag multimerization. In addition, the contribution of NC in HIV-1 assembly also relies on the presence of a stretch of basic residues located in the NTD and of charged amino acids located throughout $\mathrm{NC}$ that contribute to Gag multimerization [42]. Finally, the NC domain of Gag associated with genomic RNA is a key player in the recruitment of host cofactors of HIV-1 assembly into the viral particle. This family of proteins includes Staufen1 [43], nucleolin, [44], ABCE1 [45] and Bro1 [46], all of these proteins being reported as cofactors for HIV-1 assembly.

\subsection{Gag p6 Domain and Viral Release}

To the exception of a very recent study indicating that mutations in the C-terminal p6 domain in the Gag polyprotein interfere with $\mathrm{CA}-\mathrm{SP} 1$ processing and generate 
noninfectious particles [47], p6 is generally admitted to play no apparent role in retroviral assembly to the exception of its capacity to recruit the cellular machinery required for viral budding and release. At the cell membrane, a number of host cell components are recruited to allow the final release of the nascent particle. The most striking example is the hijacking of the Endosomal Sorting Complexes Required for Transport (ESCRT) (for revue see [48]). The primary function of the ESCRT complexes is to create internal vesicles in multivesicular bodies (MVBs)/late endosomes and to participate in the recognition, sorting and degradation of membrane molecules in lysosomes. During this process, ESCRT complexes dictate the incorporation of ubiquitinylated cargoes into budding exosomes and the pinching off of endosomal vesicles into MVBs. During retroviral assembly and budding, these complexes assist processes that are topologically related to reactions occurring during inward budding of cellular vesicles into MVBs lumen. Engagement of this pathway relies on its recruitment through initial interaction of a $\mathrm{P}(\mathrm{T} / \mathrm{S}) \mathrm{AP}$ late domain in p6 domain at the C-terminus of Gag with Tsg101 participating in ESCRT-I complex. Then the LYPXL motif in p6 interacts with the V-domain of Alix [ALG-2 (apoptosis-linked gene 2)-interacting protein X] [49]. This interaction is regulated by structural constraints in $\mathrm{p} 6$ [50]. Despite not fully understood, Gag ubiquitinylation might participate in this process as suggested by the capacity of proteasome inhibitors to reduce HIV-1 release $[51,52]$. The nature of the ubiquitin ligase participating in Gag ubiquitination is not fully elucidated. However, the PPXY motif in Gag binds members of the Nedd4 family of E3 ubiquitin ligases. Moreover, Nedd4-2 ubiquitinates Gag and may, in this way, allow the recognition by ubiquitin-binding domains within the ESCRT machinery [48]. Identifying the ubiquitin ligases required for HIV-1 budding as well as decrypting the exact role played by these enzymes and by Gag ubiquitinylation in retroviral release would provide new insight in the mechanisms of retroviral budding.

Of note, advances in the field of HIV-1 budding have been achieved in the last years with the identification of BST2/tetherin, a cellular protein found to counteract the release of assembled particles [53,54]. This GPI-anchored molecule retains virions on the surface of infected cells and within endosomes following virions internalization $[53,54]$. In wild type conditions, the colocalization of Tetherin with nascent particles is counteracted by HIV-1 Vpu [53,55]. When produced in the absence of $\mathrm{Vpu}$, viral particles accumulate in a mature form at the plasma membrane and in intracellular compartments of tetherin-expressing cells [56]. Accordingly, the host cell machinery either assists or counteracts the final virus-cell membrane scission through contacts with retroviral proteins.

\section{Cellular Compartments Supporting Gag Assembly}

\subsection{Membrane Microdomains and Viral Assembly}

The production of a HIV-1 immature particle results from targeting of Gag and GagPol precursors, viral RNA and Env glycoproteins to a unique site of assembly (Figure 2). The place where HIV-1 assembly takes place is

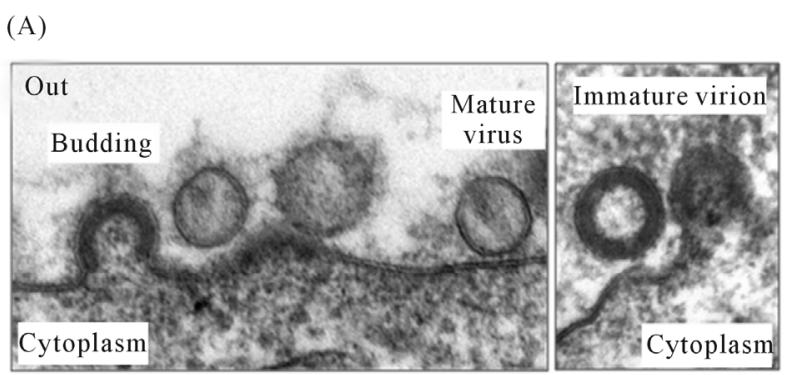

(B)
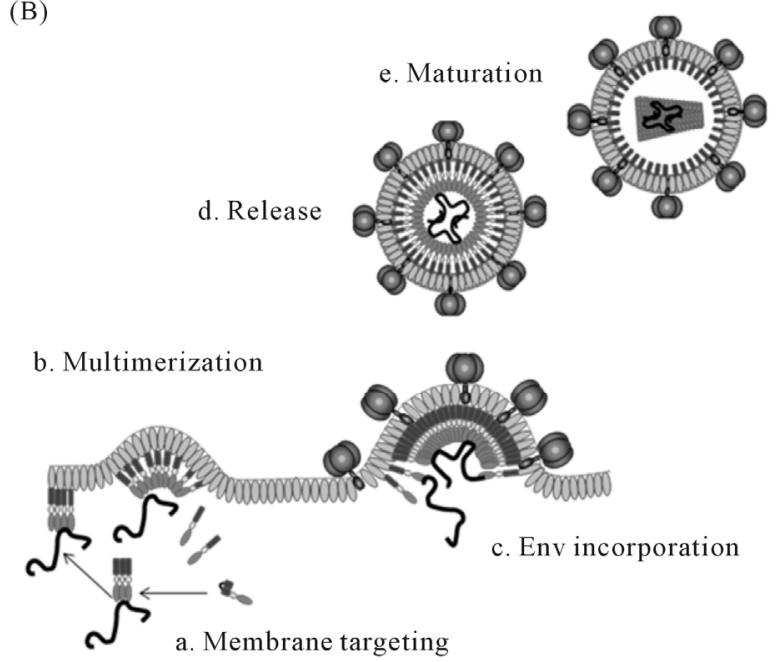

Figure 2. (A) Morphological consequences of Gag processing visualized by electron microscopy imaging; (B) Schematic representation of $\mathrm{HIV}-1$ assembly, budding and maturation. Gag precursors are addressed to the plasma membrane (a) and insert into the lipid bilayer through interaction of MA with phosphoinositides (b). Gag oligomerizes into microdomains through contacts occurring throughout the polyprotein domain. Contacts between the NC domain of Gag and full length RNA serve as a scaffold to Gag assembly and direct incorporation of the viral genome into the nascent particle. At this time, the retroviral envelope is incorporated into the viral bud (c). The viral particle is released as an immature non infectious virion (d). Once released, Gag polyprotein in the immature virion is processed by the protease. The matrix remains associated to the lipid bilayer while the mature capsid protein refolds into a cone shape structure containing the RNA dimer (e). 
still a matter of debate (reviewed in [8]). The current knowledge indicates that it may occur in distinct compartments considering the different cell types susceptible to support HIV-1 replication. In most cell types, including T lymphocytes, HIV-1 assembles predominantly at the plasma membrane. In contrast, retroviral particles were proposed to assemble and to bud into intracellular late endosomal vacuoles/multivesicular bodies (MVB) in macrophages. However, the presence of viruses in intracytoplasmic vacuoles was later reported to illustrate the presence of virions into extracellular spaces limited by membrane invaginations with the appearance of a bona fide intracellular compartment. In this context, a major argument is that the manipulation of the endocytic compartment inhibits Gag localization in endosomes without effect neither on Gag expression at the plasma membrane or on extracellular HIV-1 release [57]. To date, this question remains controversial and it is not clear whether HIV-1 has acquired different mechanisms of budding in different cell types including in macrophages. The possibility that Gag precursor could be addressed first to MVBs before being relocalized to the plasma membrane has been evoked. This model is quite similar to that proposed for HTLV-1 assembly and budding [58].

At the plasma membrane, the viral assembly is likely to be supported by lipid enriched domains, the nature of which is widely discussed [59]. This model relies first on the observation that virions are markedly enriched in specific phospholipids (cholesterol, PI(4,5)P2 phosphoinositide) relative to the plasma membrane [60]. Moreover, the incorporation of cellular proteins generally associated with membrane microdomains (namely Thy-1, CD55, CD59 GPI-anchored proteins, tetraspanins) together with the selective exclusion of proteins from these areas (CD45) are additional arguments supporting that HIV-1 assembles and buds in specific membrane microdomains [61]. Both the lipid rafts and the tetraspanin enriched domains (TEMs), despite distinct, were proposed as preferential platforms for retroviral assembly as Gag colocalizes in vivo with each domain [8]. The role of lipids rafts as assembly platforms is supported by biochemical evidences demonstrating that Gag associates with detergent-resistant membrane and by the drastic inhibition of HIV-1 release observed in cells depleted for membrane cholesterol, an essential component for raft integrity. Finally, coimmunoprecipitation of Gag with some CD81 tetraspanin pointed the possible role of tetraspanin enriched domains in retroviral assembly. The question whether Gag is targeted preferentially to pre-existing microdomains or whether these areas are structured upon Gag targeting at the plasma membrane remains to be answered.
In the context of the uncleaved Gag, the N-terminal matrix domain interacts with the lipid bilayer through the insertion of a myristic acid moiety covalently attached to the $\mathrm{Gly}_{1}$ residue at the N-terminus of MA $[62,63]$. This motif facilitates interactions of MA with phosphoinositides, mainly with phosphatidylinositol-(4,5)-bisphosphate [PI(4,5)P2], present in the cytoplasmic leaflet. Lipid binding and localization of the Gag precursor to the plasma membrane is additionally reinforced by electrostatic interactions of acidic phospholipids with a stretch of basic residues located at positions 17 - 30 in MA domain of Gag the presence [8]. NMR studies revealed that the inositol head group and the 2' acyl chain of $\mathrm{PI}(4,5) \mathrm{P}_{2}$ fit into a hydrophobic cleft in MA, promotes exposure of the sequestered myristate group, thereby promoting the stable association of the viral matrix with membranes and protein oligomerization [64,65]. Upon proteolytic processing, MA refolding decreases its capacity to bind to membranes [66].

\subsection{Molecular Interactions Required for Trafficking of Gag and Env}

The hijacking of cellular transport systems is generally required to overcome the limited capacity of most virus-encoded components to diffuse freely in the host cell cytoplasm to the site of assembly. Regarding HIV-1, early experiments based on the use of chemical inhibitors including brefeldin and monensin evidenced that Env but not Gag transport is ensured by the vesicular pathway (see [8]). A series of data reporting the capacity of wortmannin, an inhibitor of myosin light chain kinase, or of actin depolymerisation agents mycalolide $\mathrm{B}$ and cytochalasin D to reduce the transport of nascent HIV-1 protein in the host cell and to disrupts Gag compartmentalization within the polarized raft-like domains of $\mathrm{T}$ cells has suggested that the cell cytosketon assists viral particle assembly and is required for spread of HIV-1 (for review see [67]). The data supporting the active transport of Gag to the assembly site and the contribution of the cell cytoskeleton in viral assembly were reinforced by the description of direct interaction between Gag and actin and between Gag and the kinesin motor KIF-4. Finally, the association of components of actin microfilaments with highly purified HIV-1 particles provides additional support to the role of cytoskeleton in HIV-1 assembly [1]. Additional interaction between Gag and $\mathrm{hVps} 18$, Mon2 proteins and with AP1 and AP3 clathrin adaptors have been reported to assist virion assembly [68-70], suggesting that interaction between HIV and cellular proteins specialized in vesicle formation and endosome biogenesis are required during the late stages of the viral life cycle.

An important question to be answered is the exact 
place where the viral components self associate, and the locus where Gag, Env and the RNA genome encounter to assemble into a correctly folded immature particle. This question was partly solved for Rous sarcoma virus (RSV). In this model, the Gag protein undergoes a transient nuclear trafficking prior to plasma membrane transport and binds viral RNAs to form ribonuclear protein complexes that are exported from the nucleus for packaging into virus particles (for review see [71]). Regarding HIV-1, in the absence of Gag, genomic RNA accumulates at the nuclear envelope. The retroviral nucleic acids are redirected to the plasma membrane when Gag is expressed. Despite, mutations in MA relocalizing Gag to the nucleus impair HIV-1 replication [72], the role of HIV-1 Gag in triggering export of ribonucleic complexes from the nucleus remains undemonstrated conversely to RSV.

The recent development of live imaging techniques provided some the field of HIV-1 proteins trafficking. First, these approaches established that assembly of a single particle almost complete between 5 to 9 min [73]. Then, investigation of trafficking in living cells evidenced that the genomic RNA encounters monomers or low-order multimers of Gag present in the cell cytoplasm and form a subvirion complex required for anchoring of HIV-1 genome at the plasma membrane. Gag-RNA contacts are stabilized by interactions in $\mathrm{CA}_{\mathrm{CTD}}$. Once addressed to the plasma membrane, this subunit nucleates further accumulation of Gag and the complexes assemble into high-order multimers [7].

The trafficking of gp160 Env polyprotein is extremely complex (reviewed in [12]). It is synthesized by ribosomes located in the rought RE, transported to the cell membranes by the secretory pathway and finally recycled by the endosomal/lysosomal compartment before final expression at the cellular membrane. During transportation, the envelope polyprotein precursor undergoes glycosylation and proteolytic processing into mature gp120 and gp41. Direct interaction of viral proteins with the cellular lipid cargo protein TIP47 is required for HIV-1 assembly. Indeed, the inhibition of interactions between TIP47 and the matrix domain in Gag or between the intracytoplasmic domain of gp41 and TIP47 prevents the colocalization and interaction of Gag and Env in macrophages, thereby inhibiting Env incorporation into budding virions. This observation supports the notion that TIP47 is required for Gag and Env to encounter at the retroviral assembly site and for the assembly of infectious particles.

\section{Maturation of HIV-1 Virions}

HIV-1 particles are initially released from the producing cell as immature non infectious virions containing uncleaved precursors that are turned into mature fully in- fectious viruses following proteolytic processing and reorganization of the structural proteins [2]. The entire processing of Gag and GagPol precursors is finely coordinated and regulated. It requires the activity of the retroviral protease (PR), a 99 amino acids protein that relates to the family of cellular aspartyl proteases. At initial step, an unknown signal, probably based on the local concentration of GagPol precursors favors dimerization of the PR in GagPol polyprotein and autocleavage of the active enzyme. Activation of the viral protease and maturation of structural precursors need to be timely regulated to ensure the optimal maturation of the viral particle. Indeed, premature PR activation or excessive activity and inactive PR equally abolish the assembly of infectious particles [74]. Processing of HIV-1 proteins by the retroviral protease involves no strict consensus amino acid motif. The recognition of the cleavage sites is rather determined by the local conformation of the target.

Gag cleavage by the retroviral protease occurs sequentially at five specific sites (Figure 3). During this stepwise reaction, the SP1-NC junction is cleaved with greater efficiency. Then, the joint SP2-p6 and the MA$\mathrm{CA}$ regions are cleaved, allowing the release of free $\mathrm{MA}$ and p6 together with the p25 (CA-SP1) and NC-SP2 intermediates. The separation of spacer peptides is the final maturation step that turns the p25 intermediate into the mature p24 capsid protein and allows the release of the mature NC. The cleavage of HIV-1 structural proteins is accompanied by a morphologic conversion of the viral particle. When studied by electron microscopy imaging, the most critical change relates to the conversion of the electron dense ring of assembled Gag polyproteins beneath the lipid bilayer into a conical shaped capsid resulting from assembly of mature CA (Figure 2(A)). The assembly of this protein core, together with its stability and its capacity to disassemble at the appropriate time regulate viral infectivity by allowing early step of infection to occur in a new target cell. The mature core is of fullerene-type geometry. It consists of a lattice of 250 CA hexamers separated by a 9.6-nm hexamer-hexamer

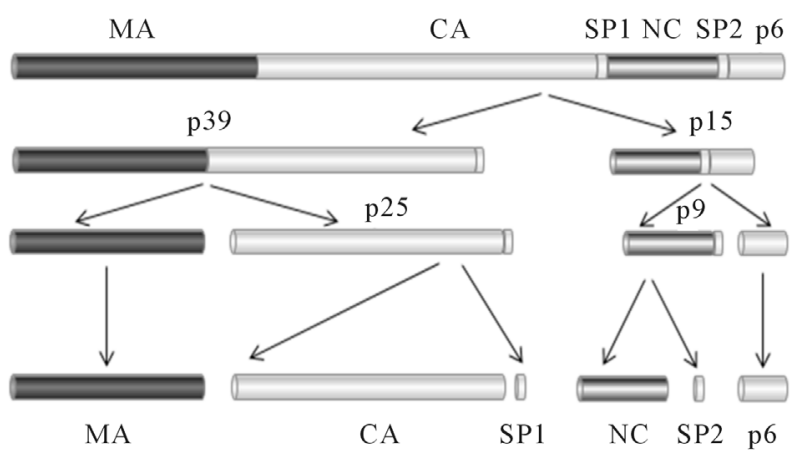

Figure 3. Schematic representation of timely processing of 


\section{Gag polyproteins.}

spacing and is closed at the narrow end by 5 pentamers and by 7 pentamers at the broad end $[2,22]$. At the molecular level, the release of the cleaved CA is accompanied by a significant refolding of the protein. The CTD rearranges into its mature position and engages intrahexamer interaction with the NTD of an adjacent molecule. The $13 \mathrm{~N}$-terminal residues refold into a $\beta$-hairpin that engages the formation of a salt bridge between Proline 1 and Aspartate 51 residues in the NTD of CA. This salt bridge is essential for proper core assembly and viral infectivity. NTD refolding was proposed to create a new dimeric interface required for appropriate assembly of the conical core. This function was recently contradicted [75], and the contribution of the $\beta$-hairpin was rather proposed to determine and stabilize the orientation of CA proteins in the mature lattice [76].

Finally, the release of mature $\mathrm{CA}$ is accompanied by production of processed MA and NC proteins. Release of fully mature $\mathrm{NC}$ is required for infectivity as it favors the condensation of the ribonucleoprotein complex and stabilizes dimers of genomic RNA [77]. Processing also lowers membrane-binding affinity of MA, reduces multimerization and results in the sequestration of the myristate moiety. Such modification may be required for appropriate membrane dissociation of viral preintegration complexes of incoming particles. Finally, the proteolytic processing of Gag also regulates Env-mediated cell-to-cell fusion, perhaps by altering the interaction between MA and the cytoplasmic tail of gp41 [78,79].

\section{New Inhibitors of HIV-1 Replication}

At the end of 2010, approximately 33.3 million people were estimated to be infected worldwide with HIV-1 (UNAIDS Global report 2010; http://www.unaids.org/ globalreport/). Significant progress has been made in the treatment of HIV-1-infected people since the introduction of highly active antiretroviral therapy (HAART) based on the combined use of nucleoside/nucleotide reverse transcriptase inhibitors (NRTIs), non-nucleoside reverse transcriptase inhibitors (NNRTIs), and/or protease inhibitors (PIs) (Figure 4). However, serious adverse effects together with the emergence of multi-drug-resistant viral strains transmitted to more than $25 \%$ of newly infected individuals are major concerns in the use of these drugs. Emergence of variants resistant to approved drugs suggests the need for not only novel compounds, but also compounds active against novel targets. A detailed understanding of HIV-1 assembly, release and maturation has made it possible to design or discover small molecules and peptides that interfere with assembly release and maturation.

\subsection{Assembly and Release Inhibitors}

The identification of active peptides as candidates for intervention at the virus assembly level is one promising strategy. As exposed above, the assemblies of Gag proteins into immature viral particles followed by proteolytic disassembly of the Gag shell to mature capsids are crucial steps for the formation of infectious HIV-1 particles. In this process the function CA in context of Gag or in assembling the conical core of viral particles is of central importance. Inhibitors that bind CA could therefore disrupt virus assembly at various steps. The identification by phage display screening of a 12-mer peptide capable to inhibit both mature and immature particles in vitro provided a proof of concept for this new class of inhibitors. This peptide termed capsid assembly inhibitor (CAI) binds residues 169 - 191 in CA and interacts with the last $\alpha$-helix of the protein [80]. A high-resolution X-ray structure of CAI in complex with CTD of HIV-1 capsid protein $\left(\mathrm{CA}_{\mathrm{CTD}}\right)$ has revealed that the peptide binds to a hydrophobic groove formed by helices 1,2 and 4 [81]. However, the CAI peptide itself fails to inhibit HIV-1 assembly in cell culture due to its inability to penetrate cells. A structure-based rational design approach known as hydrocarbon stapling has then been developed to stabilize the alpha-helical structure of CAI and convert it to a cell-penetrating peptide. The resulting molecules, named NYAD-1 and NYAD-13 efficiently disrupt HIV-1 assembly in cell cultures [82]. However, because they have a relatively low affinity for $\mathrm{CA}$, these peptides are unlikely to progress to the clinic $[80,82,83]$. Anyway, NYAD peptides should be considered as a proof of concept for cell penetrating peptide which inhibits both assembly of immature particles and core formation [80,82]. Information gained in the study of these molecules has been used as a starting point for the design of peptidomimetics and small molecule drugs targeting HIV-1 assembly and have warranted high-throughput virtual docking screens for compounds binding in the pocket formed by helices 1, 2 and 4 in CA. After selection, 2 compounds out of a series of 8 hits have been found to retain an antiviral activity. Both are active at low micromolar concentrations in cell culture to disrupt mature assembly but not immature assembly in vitro [84]. While all the above mentioned compounds act through binding to $\mathrm{CA}_{\mathrm{CTD}}$, candidate molecules screened by in silico modeling and NMR titration spectroscopy of molecules interacting with the N-terminal moiety of CA have been identified [85]. Two molecules, CAP-1 and CAP-2, have been reported to inhibit the assembly and/or the stability of the mature capsid lattice. CAP-1 interacts with the $\mathrm{CA}_{\mathrm{NTD}}$ with a $\mathrm{Kd}$ of $1 \mathrm{mM}$ and CAP-2 with a Kd of $52 \mu \mathrm{M}$. The binding sites 


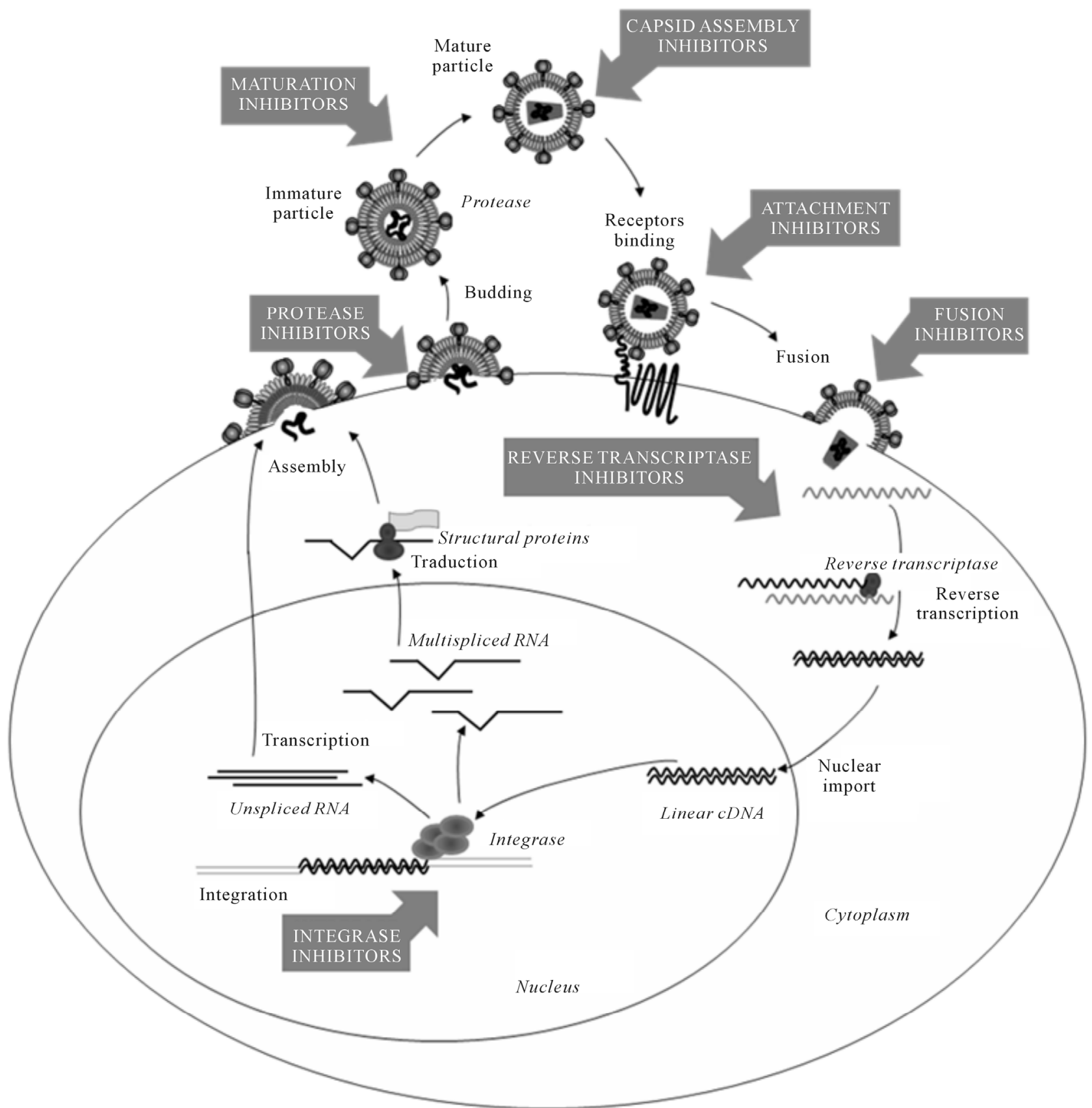

Figure 4. HIV-1 life cycle and current inhibitors of HIV-1 replication. Current anti-HIV-1 therapies inhibit reverse transcriptase and the HIV-1-encoded protease. Alternative strategies under development target the integrase, binding of the viral envelope with its receptors and fusion of the viral particle with the host cell membrane. The most recent approaches are designed to inhibit viral maturation in a protease independent way and to perturb assembly of the mature capsid.

determined by NMR perturbation experiments map to a single sequence located at the apex of a helical bundle composed of helices 1, 2, 3, 4, and 7 which have been demonstrated to be involved in an intersubunit $\mathrm{CA}_{\mathrm{NTD}^{-}}$ $\mathrm{CA}_{\mathrm{CTD}}$ interaction unique to the mature lattice. The structure of complexes formed by $\mathrm{CA}_{\mathrm{NTD}}$ and CAP-1 evidenced that upon CAP-1 binding, $\mathrm{CA}_{\mathrm{NTD}}$ undergoes conformational rearrangements with a displacement of $\mathrm{F}_{32}$ residue from its buried position in the protein core [86]. Both CAP-1 and CAP-2 block in vitro assembly of CA into helical tubes; CAP-2 has been proven to be cytotoxic, but CAP-1 was nontoxic and resulted in greater than $95 \%$ inhibition of virus replication in cell culture [85]. Morphological analysis indicates that virions pro- 
duced in the presence of CAP-1 are more heterogeneous in size than those produced in its absence and display aberrant core morphology. Based on the measured CAP-1-CA NTD $_{\text {affinity, it is estimated that as few as } \sim 25}$ molecules of CAP-1 per particle are sufficient to inhibit the formation of a functional core particle. As CAI and its derivatives, CAP-1 disturbs interaction with $\mathrm{CA}_{\mathrm{NTD}^{-}}$ $\mathrm{CA}_{\mathrm{CTD}}$ interface. The extensive knowledge gained in studying these inhibitors and their molecular targets has paved the way for subsequent efforts to screen for small molecules inhibitors of HIV-1 assembly and/or maturation.

Screens using a cell-based assay that supports a complete viral replication cycle, identified a series of compounds that interfere with assembly and uncoating. Among these compounds PF-74 presents an antiviral activity with an $\mathrm{EC}_{50}$ of $0.6 \mu \mathrm{M}$. This molecule, unlike CAP-1 does not induce conformational change but rather binds in a pocket defined by helices 3, 4, 5 and 7 into the $\mathrm{CA}_{\mathrm{NTD}}-\mathrm{CA}_{\mathrm{CTD}}$ interface. Interestingly, PF-74 was also capable to act early during infection by altering postentry uncoating. All these studies validate assembly and more precisely both the NTD and the CTD of HIV-1 capsid protein as potential antiviral targets.

To complete the viral life cycle, following assembly, HIV-1 particles are subsequently released from the plasma membrane of infected cells. Release of the virus requires the Gag protein and the active participation of multiple host proteins [88]. As mentioned above, the p6 region of Gag known as late domain, contains a highly conserved $\mathrm{P}(\mathrm{T} / \mathrm{S}) \mathrm{AP}$ tetrapeptide motif which binds to the ESCRT-I component Tsg101 and LYPXL which interacts with Alix ([48]). Inhibition of Tsg101 synthesis or overexpression of the N-terminal Gag binding domain of Tsg101 (TSG-5') severely impairs virus production by arresting the release of viral particles from the plasma membrane of host cells. In the same way, overexpression of the Gag-binding domain of Alix (V-domain) also blocks HIV-1 release [89]. Even if the overexpression of TSG5' or Alix V-domain inhibits virus budding in tissue culture conditions, it seems hard to imagine they can be used for therapeutic application. As high resolution structural information is available for p6-Tsg101 and p6-Alix [90] several research teams have been able to achieve a rational design of budding inhibitors. A PTAP-based peptide which presents an increased affinity for Tsg101 has been designed [91]. Using a bacterial reverse two hybrid system a library of $3.210^{6}$ cyclic peptides have been screened to identify hits that interfere with p6-Tsg101 interaction. Five peptides can disrupt this interaction and inhibit HIV-1 release [92]. Collectively, all these results support the notion that small therapeutic molecules that inhibit specific oligomerization or multimerization of Gag or CA or contacts between Gag and host proteins represent a significant challenge for the development of new classes of antiretrovirals.

\subsection{Maturation Inhibitors}

\subsubsection{Chemical Agents Targeting SP1 Junction and Antiviral Properties}

As the proteolytic processing of Gag is conditioned by the functionality of the viral protease and by the accessibility of the recognition site in Gag, strategies aimed at interfering either with PR enzymatic activity or to reduce access to protein substrate have been considered in the development of anti-HIV-1 drugs. The later concept is represented by a new class of HIV-1 antivirals referred to as maturation inhibitors that have been developed and tested in phase IIb clinical trials. This class of compounds developed in the recent years is characterized by its ability to inhibit proteolytic maturation of Gag independently of an inhibition of protease activity. The lead drug of this pharmacologic class is betulinic acid (BA), a triterpene compound isolated from the clove-like plant Sygizum claviflorum. This molecule has been initially identified as an anti-cancer agent with significant activity against melanoma. In the last years it has been identified as an anti-HIV-1 molecule [93]. Modification of side chains at positions $\mathrm{C} 3$ and $\mathrm{C} 28$ in the betulinic acid scaffold has been used to derive a library of compounds that has been evaluated in vitro for its inhibitory properties [94] (Figure 5). Among these molecules, an acyl derivative of the $\mathrm{C} 3$ hydroxyl, 3-O-(3',3'-dimethylsuccinyl) betulinic acid, later renamed bevirimat (BVM) or PA457 or DSB, displays a mean $\mathrm{IC}_{50}$ value of approximately $10 \mathrm{nM}$ against primary HIV-1 isolates [95] and retains a therapeutic index greater than 20,000 in H9 lymphocytes [94]. The viral steps inhibited by these molecules have been investigated in depth. No activity against reverse transcriptase or integration has been observed for the lead compounds [94,96]. Marginally, triterpenes have been reported to inhibit HIV-1 protease dimerization, a prerequisite for enzymatic activation [97]. However, BVM does not exhibit a significant inhibitory effect on protease cleavage when a synthetic peptide or recombinant Gag are used as substrates [95]. Two possible mode of action have been identified as primary mechanisms for betulinic acid-derived molecules. Compounds with modifications at the carboxylic group in position C28 interfere with HIV-1 entry into target cells [98]. Such effect has been reported for the RPR103611 and IC9564 derivatives [98]. These compounds both inhibited cell-cell fusion induced by a variety of viral isolates, without interfering with the binding of viral particles to the target cell. However their respective mechanisms of action may differ 
(a)

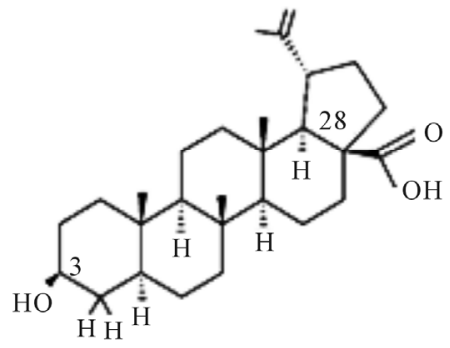

Betulinic acid

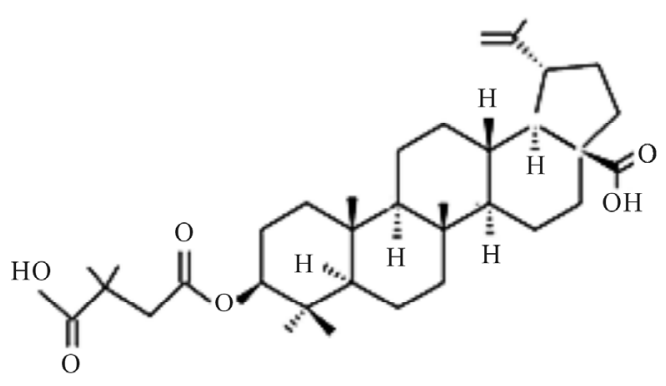

BVM

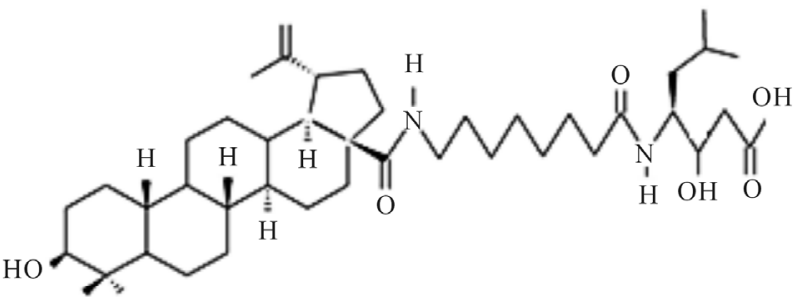

(b)

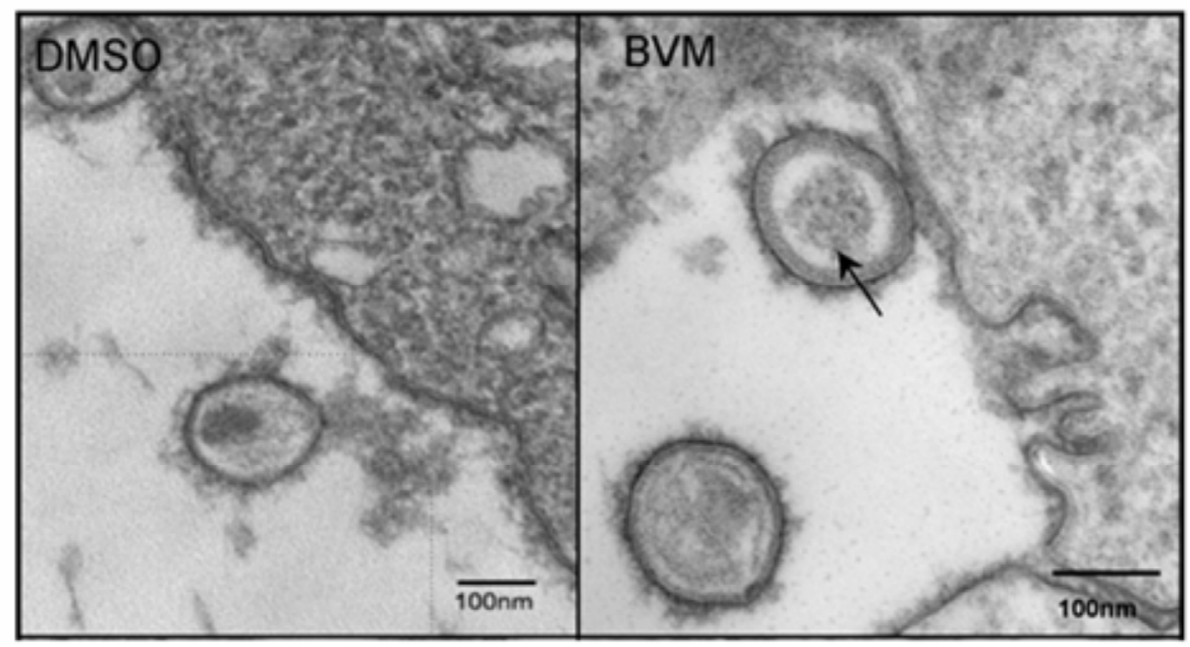

Figure 5. Inhibitors of HIV-1 maturation and consequences on viral core morphology. (a) Structure of betulinic acid and some derivatives. C-3 and C-28 atoms are marked; (b) Morphology of HIV-1 particles produced from untreated cells or in the presence of bevirimat (BVM). The arrow indicates a viral particle with a partial immature morphology. The scale is indicated by a bar.

in some point since the prolonged use of RPR103611 favored the acquisition by the virus of mutations in gp41 [99] and resistance to IC9564 was associated to mutations in gp120 [100]. Although not elucidated, the mechanism of action of $\mathrm{C} 28$ derivatives of betulinic acid resembles that of T20 inhibitor and may rely on the inhibition of a late step of the fusion process, occurring after lipid mixing [101]. Conversely to C28-modified BA derivatives, molecules composed of a triterpenic scaffold with modification of hydroxylic group at position C3 do 
not inhibit viral entry but rather interfere with late stages of HIV-1 assembly. This inhibitory effect has been initially identified for the lead compounds BA and BVM. These compounds, when added to a HIV-1 producing cell culture, induce a dose-dependent change in the viral protein profile both in cells and in viral particles [95]. The amount of processed $\mathrm{p} 24$ protein decreases in favor of the immature p25 protein reflecting unprocessed CA-SP1 junctions. This phenotype is reminiscent of that observed for HIV-1 bearing mutations in CA or at SP1 junction that abolish CA-SP1 processing [30]. Consistent with the capacity of BA-derived inhibitors to interfere with viral maturation, the capacity of viral particles to be released in the extracellular medium remains unaffected. Used in de novo infection experiments, these viruses are competent for binding and fusion events, but are unable to reverse transcribe genomic RNA into proviral DNA [102]. From the morphological point of view, these particles show aberrant core condensation when studied in electron microscopy. The inner capsid instead of coneshaped is acentric, spherical and cohabits with patches of uncleaved Gag beneath the lipid bilayer [94]. Cryo-EM analysis has recently revealed that they contain an incomplete Gag hexameric shell underlying the viral envelope lacking the NC domain [103]. The presence of dense material at the center of the particle probably reflects the release of CA/CA-SP1 molecule in quantities sufficient to assemble small capsid with altered size and shape or alternatively that of ribonucleic complexes mainly comprising NC and genomic RNA (Figure 5(b)). Thus, it is conceivable that the small amounts of incompletely processed Gag molecules generated by treatment with inhibitors are sufficient to interfere with the ordered maturation of Gag, and inhibit HIV-1 infectivity in a trans-dominant manner as proposed [104]. This defect is usually associated with incomplete maturation in response to SP1 mutations. Isolation experiments have established that the corresponding core structure is unstable [105].

The region binding BA and BVM is not formally determined. However, a number of studies provided support on the role of the CA-SP1 junction in Gag. Indeed, BVM, despite inhibiting VLPs in Sf9 insect cells infected with a recombinant baculovirus expressing HIV-1 or SIV $_{\text {mac251 }}$ Gag precursors with $\mathrm{IC}_{50}$ of $10 \mu \mathrm{M}$ and $20 \mu \mathrm{M}$ respectively, was unable to block assembly of MLV Pr72Gag [106]. In contrast, BVM efficiently blocks assembly of a MLV-HIV-1 chimera containing SP1-NC-p6 domains from HIV-1 and MA-CA domains from MLV with an $\mathrm{IC}_{50}$ of $30 \mu \mathrm{M}$. Altogether these observations lead to the conclusion that the main target on Gag is SP1, and suggested that other upstream Gag region(s) might contribute to BVM reactivity in that particular model.
The fact that BVM and BA lack activity against HIV-2 and SIV provides support to the hypothesis that BA-derived molecules act at the level of CA-SP1 maturation [102]. Indeed, these viruses display relatively low genetic homology with HIV-1 in this particular domain (Figure 6). Modeling analysis and sequence alignment indicate that HIV-1 and SIV $_{\text {mac }}$ CA-SP1 differ regarding their hydrophobicity supporting that this intrinsic property may dictate sensitivity to BVM. In addition, mutations at the CA-SP1 junction at positions 362 and 363 in Gag render SIV sensitive to BVM [105]. Mutations acquired by BVM-resistant viruses are expected not to modify the structure of this particular domain and to increase its hydrophobicity.

Going deeper into the mode of action of BA and BAderived molecules, the capacity of these molecules to inhibit Gag processing by blocking access of the retroviral protease to the Gag precursor or alternatively through fixing the Gag shell into as configuration unfavorable to its proteolytic processing has been questioned. The requirement for a higher order oligomeric Gag structure for BVM activity has been established. Indeed, the inhibitor is inactive on recombinant Gag in solution unable to assemble. To the opposite, BVM inhibits CA-SP1 processing of in vitro preassembled Gag [95]. Moreover, the mode of action of BVM apparently requires the binding to Gag. This mechanism is supported by its selective incorporation into HIV-1 immature particles at a 1:1 stoechiometry [107]. The observation that mutations in CA-SP1 conferring resistance to this molecule abolish incorporation finally suggested that a specific binding of the inhibitor to the Gag shell is required. Accordingly, the model of action of BVM and derived molecules currently accepted indicates that 1) BVM binds Gag when present in a specific conformation that is unique into the immature lattice; 2) the bioactive molecule inhibits interactions within the Gag hexamer; 3) the SP1 linker domain participates in the interaction between Gag and BVM. A model was proposed in which a trimer of BVM, stabilized by intermolecular interaction of the hydrophobic betulinic acid core, associates with the CA-SP1 junction present as trimers within the Gag lattice [107]. This model would explain why BVM is inefficient at inhibiting protease-dependent processing of soluble Gag.

\subsubsection{Clinical Evaluation of Bevirimat and Betulinic Acid-Derivatives}

The marked capacity of BVM and BA derivatives to potently inhibit HIV-1 replication in vitro together with toxicological studies showing a very good tolerance of this series of molecules in rat and marmoset models, a good absorption after oral administration together with the lack of serious adverse effects [108] prompted further 


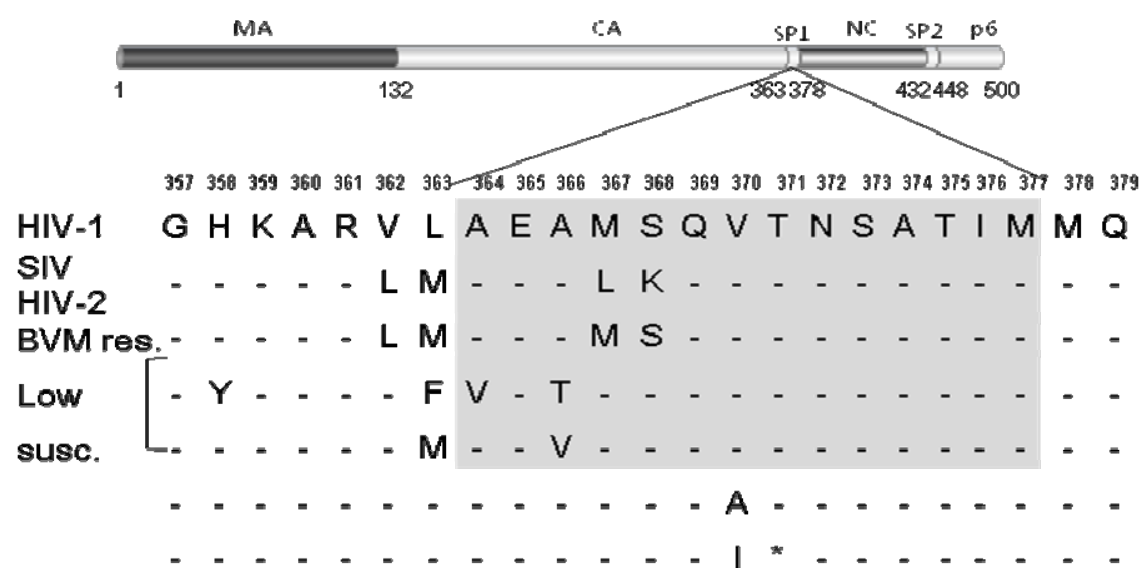

Figure 6. Representation of CA-SP1 sequences in HIV-1, HIV-2 and SIV and of mutations acquired in this region by HIV-1 viruses in response to bevirimat treatment (BVM res). The deletion of amino acid at position 8 in SP1 of low susceptible (Low susc.) viruses is indicated by*.

evaluation of BVM in vitro and in clinical trials. However, soon after discovery, BA-derived molecules have been reported to generate the acquisition of mutation-associated resistances. In vitro, serial passage of HIV- $1_{\mathrm{NL} 4.3}$ in the presence of DSB favored the emergence of resistant strains. Individual mutations responsible for DSB resistance have been mapped both to residues immediately flanking the CA-SP1 cleavage site and to the $\mathrm{C}$-terminus of CA. No other change either in the protease or in the other domain of Gag correlates with DSB resistance. Six individual mutations have been first identified: H226Y, L231F, and L231M in CA and A1V, A3T, A3V in SP1. [95,105,109]. L231M and A1V mutations decrease BVM susceptibility by 37.6 -fold and more than 77.5 -fold, respectively [110]. In phase $1 / 2$ and $2 \mathrm{a}$ clinical trials, 50 to $60 \%$ of HIV-1 patients experience resistance to BVM [110]. From the genotypic point of view, the in vivo situation appears quite different of that established in vitro since patient isolates do not contain the corresponding mutations [111]. Instead, a predictive value for BVM resistance has been attributed to polymorphisms in a QVT motif at positions 6, 7, and 8 in SP1 [110-113]. In patients, the presence of the T8 deletion often coincided with the presence of a polymorphism at $\mathrm{T} 7$, making the role of the $\mathrm{T} 8$ deletion in resistance more difficult to assess. More recently, SP1 residue 7 of the Gag protein has been proposed to be the primary determinant for SP1 polymorphism associated drug resistance to BVM for subtype $\mathrm{C}$ isolates [114]. Nevertheless, the $\mathrm{T}_{371}$ deletion plays a less critical role than V7A in resistance to BVM [112]. This deletion is observed in PI-experienced patients and is proposed to be co-selected with treatment with protease inhibitors. Polymorphism study has finally revealed that in vivo, the CA protein-V230I mutation is also a major mutation conferring resistance to BVM [112]. From these studies it appears that the knowledge on molecular mechanisms of inhibition by BVM needs to be significantly improved before BA-derived molecules are further optimized.

Of note, the capacity of BVM and BA-derived molecules to inhibit HIV-1 maturation is shared by another inhibitor of HIV-1 maturation isolated in the same time. PF-46396, a pyridone-based compound has been discovered as a hit from high-throughput full HIV-1 replication screen of inhibitors [115]. This small molecule has been further identified as an inhibitor of viral maturation. As previously observed for BVM and BA-derived compounds, PF-46396 interferes specifically with the cleavage of the CA-SP1 without effect on PR activity [116]. Selection pressure exerted by PF-46396 yields the acquisition of a I201V mutation in the C-terminal region of HIV-1, a mutation that also confers resistance to BVM. Moreover, an HIV-1 mutant with the BVM-induced SP1A1V mutation displays resistance to PF-46396. Accordingly, both molecules have been proposed to share the same mechanism of action despite their distant structural relationships.

\subsubsection{Perspectives in the Study of Maturation Inhibitors}

The future optimization of triterpene compounds has been evoked. Indeed, chemical modifications at both $\mathrm{C}-3$ and $\mathrm{C}-28$ result in bi-functional $\mathrm{BA}$ derivatives. [[N[3 $\beta$-O-3',3'-Dimethylsuccinyl-lup-20(29)-en-28-oyl]-7aminoheptyl]-carbamoyl]methane (A12-2) is one of the most potent BA derivatives that inhibits HIV-1 replication at both maturation and entry steps [117]. These molecules are certainly of interest to target simultaneously early and late steps of HIV-1 replication. In addition, modification BA with insertion of a shorter C-28 side 
chain, an equivalent of CONH- $\left(\mathrm{CH}_{2}\right)_{\mathrm{n}} \mathrm{R}$ with $\mathrm{n}$ being 4 or 5 , results in optimal anti-HIV-2 activity [118]. This compound acts by targeting the V3 loop of gp120. Accordingly, these compounds could benefit to HIV-2 infected patients.

In addition, a large panel of areas remains to be investigated regarding the mode of action of BA-derived compounds and the resistance acquired in response to treatment. The first area regards the defects generated at the level of virus assembly by this series of molecules. This includes possible consequences of genomic RNA packaging. First, structural studies will be of help to define the capacity of SP1 junction to oligomerize in the presence of BA-derived molecules. Indeed, during assembly SP1 domain that folds into an amphipathic helix, assemble via hydrophobic and hydrophilic contacts [119]. Investigating the morphology of VLPs produced in the absence of viral protease from mammalian cells maintained in the presence of these molecules. Second, SP1 domain participates in contacts with SL3 RNA loop as shown RMN study of $\mathrm{CA}_{148-231}-\mathrm{SP} 1-\mathrm{NC}_{1-55} / \mathrm{SL} 3$ complexes [120]. HIV-1 RNA dimerization and Gag maturation are intimately linked [38]. Formation of a uniform RNA dimer is acquired after complete virion maturation since protease deficient viruses fail to stably dimerize genomic RNA [74]. Recently, evidence was provided for the contribution of Gag cleavage products in stabilizing genomic RNA dimers. Indeed, the initial RNA dimer is stabilized during the primary SP1-NC cleavage and complete RNA dimerization depends of ensuing proteolytic processing. Accordingly, perturbations of Gag processing might affect viral infectivity through alteration of RNA dimer stabilization. The contribution of such mechanisms in inhibitory effects of BA and derived compounds needs to be investigated.

In summary, despite the intensive investigation devoted to the study of HIV-1 assembly, release and maturation during the past 25 years, the precise molecular mechanisms required to assemble and to maturate HIV-1 virions are far from elucidated. The recent advances in the field have demonstrated that the identification of these crucial steps will offer new ways to develop bioactive molecules capable of inhibiting the replication cycle of the virus. The many examples mentioned in this review of molecules that have an antiviral effect by targeting viral assembly, release or maturation, show that efforts to elucidate the antiviral mechanisms of this family of anti-viral compounds will not only lead to the development of new bioactive molecules used in infected patients but will also help to better understand the biology of HIV-1.

\section{Acknowledgements}

We are grateful to members of the laboratory for helpful discussions. Research in our laboratory is supported by the French AIDS Agency ANRS, by the CNRS-UM1UM2 and Sidaction. We apologize to all authors whose work could not be included in this review due to space limitations.

\section{REFERENCES}

[1] C. Giroud, N. Chazal and L. Briant, "Cellular Kinases Incorporated into HIV-1 Particles: Passive or Active Passengers?" Retrovirology, Vol. 8, 2011, p. 71.

[2] C. S. Adamson and E. O. Freed, "Human Immunodeficiency Virus Type 1 Assembly, Release, and Maturation," Advances in Pharmacology, Vol. 55, 2007, pp. 347-387. doi:10.1016/S1054-3589(07)55010-6

[3] J. A. Briggs, M. N. Simon, I. Gross, H. G. Krausslich, S. D. Fuller, V. M. Vogt and M. C. Johnson, "The Stoichiometry of Gag Protein in HIV-1," Nature Structural \& Molecular Biology, Vol. 11, No. 7, 2004, pp. 672-675. doi: $10.1038 / \mathrm{nsmb} 785$

[4] S. D. Fuller, T. Wilk, B. E. Gowen, H. G. Krausslich and V. M. Vogt, "Cryo-Electron Microscopy Reveals Ordered Domains in the Immature HIV-1 Particle," Current Biology, Vol. 7, No. 10, 1997, pp. 729-738. doi:10.1016/S0960-9822(06)00331-9

[5] T. Wilk, I. Gross, B. E. Gowen, T. Rutten, F. de Haas, R. Welker, H. G. Krausslich, P. Boulanger and S. D. Fuller, "Organization of Immature Human Immunodeficiency Virus Type 1," Journal of Virology, Vol. 75, No. 2, 2001, pp. 759-771. doi:10.1128/JVI.75.2.759-771.2001

[6] J. A. Briggs, K. Grunewald, B. Glass, F. Forster, H. G. Krausslich and S. D. Fuller, "The Mechanism of HIV-1 Core Assembly: Insights from Three-Dimensional Reconstructions of Authentic Virions," Structure, Vol. 14, No. 1, 2006, pp. 15-20. doi:10.1016/j.str.2005.09.010

[7] S. B. Kutluay and P. D. Bieniasz, "Analysis of the Initiating Events in HIV-1 Particle Assembly and Genome Packaging," PLoS Pathogens, Vol. 6, No. 11, 2010, e1001200. doi:10.1371/journal.ppat. 1001200

[8] A. Ono, "Relationships between Plasma Membrane Microdomains and HIV-1 Assembly," Biology of the Cell, Vol. 102, No. 6, 2010, pp. 335-350. doi:10.1042/BC20090165

[9] A. Alfadhli, D. Huseby, E. Kapit, D. Colman and E. Barklis, "Human Immunodeficiency Virus Type 1 Matrix Protein Assembles on Membranes as a Hexamer," Journal of Virology, Vol. 81, No. 3, 2007, pp. 1472-1478. doi:10.1128/JVI.02122-06

[10] A. Alfadhli, R. L. Barklis and E. Barklis, "HIV-1 Matrix Organizes as a Hexamer of Trimers on Membranes Containing Phosphatidylinositol-(4,5)-bisphosphate," Virology, Vol. 387, No. 2, 2009, pp. 466-472. doi:10.1016/j.virol.2009.02.048

[11] N. Chazal, B. Gay, C. Carriere, J. Tournier and P. Boulanger, "Human Immunodeficiency Virus Type 1 MA De- 
letion Mutants Expressed in Baculovirus-Infected Cells: Cis and Trans Effects on the Gag Precursor Assembly Pathway," Journal of Virology, Vol. 69, 1995, pp. 365-375.

[12] M. A. Checkley, B. G. Luttge and E. O. Freed, "HIV-1 Envelope Glycoprotein Biosynthesis, Trafficking, and Incorporation," Journal of Molecular Biology, Vol. 410, No. 4, 2011, pp. 582-608. doi:10.1016/j.jmb.2011.04.042

[13] K. Lu, X. Heng and M. F. Summers, "Structural Determinants and Mechanism of HIV-1 Genome Packaging," Journal of Molecular Biology, Vol. 410, No. 4, 2011, pp. 609-633. doi:10.1016/j.jmb.2011.04.029

[14] D. E. Ott, L. V. Coren and T. D. Gagliardi, "Redundant Roles for Nucleocapsid and Matrix RNA-Binding Sequences in Human Immunodeficiency Virus Type 1 Assembly," Journal of Virology, Vol. 79, No. 22, 2005, pp. 13839-13847. doi:10.1128/JVI.79.22.13839-13847.2005

[15] C. P. Jones, S. A. Datta, A. Rein, I. Rouzina and K. Musier-Forsyth, "Matrix Domain Modulates HIV-1 Gag's Nucleic Acid Chaperone Activity via Inositol Phosphate Binding," Journal of Virology, Vol. 85, No. 4, 2011, pp. 1594-1603. doi:10.1128/JVI.01809-10

[16] S. A. Datta, F. Heinrich, S. Raghunandan, S. Krueger, J. E. Curtis, A. Rein and H. Nanda, "HIV-1 Gag Extension: Conformational Changes Require Simultaneous Interaction with Membrane and Nucleic Acid," Journal of Molecular Biology, Vol. 406, No. 2, 2011, pp. 205-214. doi:10.1016/j.jmb.2010.11.051

[17] J. A. Briggs, M. C. Johnson, M. N. Simon, S. D. Fuller and V. M. Vogt, "Cryo-Electron Microscopy Reveals Conserved and Divergent Features of Gag Packing in Immature Particles of Rous Sarcoma Virus and Human Immunodeficiency Virus," Journal of Molecular Biology, Vol. 355 , No. 1, 2006, pp. 157-168. doi:10.1016/j.jmb.2005.10.025

[18] T. R. Gamble, S. Yoo, F. F. Vajdos, U. K. von Schwedler, D. K. Worthylake, H. Wang, J. P. McCutcheon, W. I. Sundquist and C. P. Hill, "Structure of the CarboxylTerminal Dimerization Domain of the HIV-1 Capsid Protein," Science, Vol. 278, No. 5339, 1997, pp. 849-853. doi:10.1126/science.278.5339.849

[19] B. K. Ganser-Pornillos, A. Cheng and M. Yeager, "Structure of Full-Length HIV-1 CA: A Model for the Mature Capsid Lattice," Cell, Vol. 131, No. 1, 2007, pp. 70-79. doi:10.1016/j.cell.2007.08.018

[20] S. Li, C. P. Hill, W. I. Sundquist and J. T. Finch, "Image Reconstructions of Helical Assemblies of the HIV-1 CA Protein," Nature, Vol. 407, No. 6802, 2000, pp. 409-413. doi:10.1038/35030177

[21] J. A. Briggs, T. Wilk, R. Welker, H. G. Krausslich and S. D. Fuller, "Structural Organization of Authentic, Mature HIV-1 Virions and Cores," The EMBO Journal, Vol. 22, No. 7, 2003, pp. 1707-1715. doi:10.1093/emboj/cdg143

[22] B. K. Ganser-Pornillos, M. Yeager and W. I. Sundquist, "The Structural Biology of HIV Assembly," Current Opinion in Structural Biology, Vol. 18, No. 2, 2008, pp. 203-217. doi:10.1016/j.sbi.2008.02.001

[23] D. Ivanov, O. V. Tsodikov, J. Kasanov, T. Ellenberger, G.
Wagner and T. Collins, "Domain-Swapped Dimerization of the HIV-1 Capsid C-Terminal Domain," Proceedings of the National Academy of Sciences USA, Vol. 104, No. 11, 2007, pp. 4353-4358. doi:10.1073/pnas.0609477104

[24] E. K. Franke, H. E. Yuan and J. Luban, "Specific Incorporation of Cyclophilin A into HIV-1 Virions," Nature, Vol. 372, No. 6504, 1994, pp. 359-362. doi: $10.1038 / 372359 \mathrm{a} 0$

[25] M. Thali, A. Bukovsky, E. Kondo, B. Rosenwirth, C. T. Walsh, J. Sodroski and H. G. Göttlinger, "Functional Association of Cyclophilin A with HIV-1 Virions," Nature, Vol. 372, No. 6504, 1994, pp. 363-365. doi: $10.1038 / 372363 \mathrm{a} 0$

[26] D. Braaten, E. K. Franke and J. Luban, "Cyclophilin A Is Required for the Replication of Group M Human Immunodeficiency Virus Type 1 (HIV-1) and Simian Immunodeficiency Virus SIV(CPZ)GAB But Not Group O HIV-1 or Other Primate Immunodeficiency Viruses," Journal of Virology, Vol. 70, 1996, pp. 4220-4227.

[27] T. Hatziioannou, D. Perez-Caballero, S. Cowan and P. D. Bieniasz, "Cyclophilin Interactions with Incoming $\mathrm{Hu}$ man Immunodeficiency Virus Type 1 Capsids with Opposing Effects on Infectivity in Human Cells," Journal of Virology, Vol. 79, No. 1, 2005, pp. 176-183. doi:10.1128/JVI.79.1.176-183.2005

[28] D. M. Sayah, E. Sokolskaja, L. Berthoux and J. Luban, "Cyclophilin A Retrotransposition into TRIM5 Explains Owl Monkey Resistance to HIV-1," Nature, Vol. 430, No. 6999, 2004, pp. 569-573. doi:10.1038/nature02777

[29] R. C. Craven, A. E. Leure-duPree, C. R. Erdie, C. B. Wilson and J. W. Wills, "Necessity of the Spacer Peptide between CA and NC in the Rous Sarcoma Virus Gag Protein," Journal of Virology, Vol. 67, 1993, pp. 62466252.

[30] M. A. Accola, S. Hoglund and H. G. Gottlinger, "A Putative Alpha-Helical Structure Which Overlaps the Capsid-p2 Boundary in the Human Immunodeficiency Virus Type 1 Gag Precursor Is Crucial for Viral Particle Assembly," Journal of Virology, Vol. 72, 1998, pp. 20722078.

[31] S. A. Datta, L. G. Temeselew, R. M. Crist, F. Soheilian, A. Kamata, J. Mirro, D. Harvin, K. Nagashima, R. E. Cachau and A. Rein, "On the Role of the Sp1 Domain in Hiv-1 Particle Assembly: A Molecular Switch?” Journal of Virology, Vol. 85, No. 9, 2011, pp. 4111-4121. doi:10.1128/JVI.00006-11

[32] E. R. Wright, J. B. Schooler, H. J. Ding, C. Kieffer, C. Fillmore, W. I. Sundquist and G. J. Jensen, "Electron Cryotomography of Immature HIV-1 Virions Reveals the Structure of the CA and SP1 Gag Shells," The EMBO Journal, Vol. 26, 2007, pp. 2218-2226. doi:10.1038/sj.emboj.7601664

[33] C. Liang, J. Hu, R. S. Russell, A. Roldan, L. Kleiman and M. A. Wainberg, "Characterization of a Putative AlphaHelix across the Capsid-SP1 Boundary That Is Critical for the Multimerization of Human Immunodeficiency Virus Type 1 Gag," Journal of Virology, Vol. 76, No. 22, 
2002, pp. $11729-11737$. doi:10.1128/JVI.76.22.11729-11737.2002

[34] B. Gay, J. Tournier, N. Chazal, C. Carriere and P. Boulanger, "Morphopoietic Determinants of HIV-1 Gag Particles Assembled in Baculovirus-Infected Cells," Virology, Vol. 247, No. 2, 1998, pp. 160-169. doi:10.1006/viro.1998.9237

[35] X. F. Yu, Z. Matsuda, Q. C. Yu, T. H. Lee and M. Essex, "Role of the C Terminus Gag Protein in Human Immunodeficiency Virus Type 1 Virion Assembly and Maturation," Journal of General Virology, Vol. 76, No. 12, 1995, pp. 3171-3179. doi:10.1099/0022-1317-76-12-3171

[36] L. V. Coren, J. A. Thomas, E. Chertova, R. C. Sowder, T. D. Gagliardi, R. J. Gorelick and D. E. Ott, "Mutational Analysis of the C-Terminal Gag Cleavage Sites in Human Immunodeficiency Virus Type 1," Journal of Virology, Vol. 81, No. 18, 2007, pp. 10047-10054. doi:10.1128/JVI.02496-06

[37] D. Lener, V. Tanchou, B. P. Roques, S. F. Le Grice and J. L. Darlix, "Involvement of HIV-I Nucleocapsid Protein in the Recruitment of Reverse Transcriptase into Nucleoprotein Complexes Formed in Vitro," Journal of Biological Chemistry, Vol. 273, No. 50, 1998, pp. 33781-33786. doi:10.1074/jbc.273.50.33781

[38] M. Ohishi, T. Nakano, S. Sakuragi, T. Shioda, K. Sano and J. Sakuragi, "The Relationship between HIV-1 Genome RNA Dimerization, Virion Maturation and Infectivity," Nucleic Acids Research, Vol. 39, No. 8, 2010, pp. 3404-3417. doi:10.1093/nar/gkq1314

[39] A. Rein, L. E. Henderson and J. G. Levin, "Nucleic-AcidChaperone Activity of Retroviral Nucleocapsid Proteins: Significance for Viral Replication," Trends in Biochemical Sciences, Vol. 23, No. 8, 1998, pp. 297-301. doi:10.1016/S0968-0004(98)01256-0

[40] R. J. Gorelick, D. J. Chabot, A. Rein, L. E. Henderson and L. O. Arthur, "The Two Zinc Fingers in the Human Immunodeficiency Virus Type 1 Nucleocapsid Protein Are Not Functionally Equivalent," Journal of Virology, Vol. 67, 1993, pp. 4027-4036.

[41] Y. Zhang, H. Qian, Z. Love and E. Barklis, "Analysis of the Assembly Function of the Human Immunodeficiency Virus Type 1 Gag Protein Nucleocapsid Domain," Journal of Virology, Vol. 72, 1998, pp. 1782-1789.

[42] S. Sandefur, R. M. Smith, V. Varthakavi and P. Spearman, "Mapping and Characterization of the N-Terminal I Domain of Human Immunodeficiency Virus Type 1 Pr55 (Gag)," Journal of Virology, Vol. 74, No. 16, 2000, pp. 7238-7249. doi:10.1128/JVI.74.16.7238-7249.2000

[43] A. J. Mouland, J. Mercier, M. Luo, L. Bernier, L. DesGroseillers and E. A. Cohen, "The Double-Stranded RNABinding Protein Staufen Is Incorporated in Human Immunodeficiency Virus Type 1: Evidence for a Role in Genomic RNA Encapsidation," Journal of Virology, Vol. 74, No. 12, 2000, pp. 5441-5451. doi:10.1128/JVI.74.12.5441-5451.2000

[44] E. Bacharach, J. Gonsky, K. Alin, M. Orlova and S. P. Goff, "The Carboxy-Terminal Fragment of Nucleolin In- teracts with the Nucleocapsid Domain of Retroviral Gag Proteins and Inhibits Virion Assembly," Journal of Virology, Vol. 74, No. 23, 2000, pp. 11027-11039. doi:10.1128/JVI.74.23.11027-11039.2000

[45] J. R. Lingappa, J. E. Dooher, M. A. Newman, P. K. Kiser and K. C. Klein, "Basic Residues in the Nucleocapsid Domain of Gag Are Required for Interaction of HIV-1 Gag with ABCE1 (HP68), a Cellular Protein Important for HIV-1 Capsid Assembly," Journal of Biological Chemistry, Vol. 281, 2006, pp. 3773-3784. doi:10.1074/jbc.M507255200

[46] S. Popov, E. Popova, M. Inoue and H. G. Gottlinger, "Divergent Brol Domains Share the Capacity to Bind Human Immunodeficiency Virus Type 1 Nucleocapsid and to Enhance Virus-Like Particle Production," Journal of Virology, Vol. 83, No. 14, 2009, pp. 7185-7193. doi:10.1128/JVI.00198-09

[47] J. Votteler, L. Neumann, S. Hahn, F. Hahn, P. Rauch, K. Schmidt, N. Studtrucker, S. M. Solbak, T. Fossen, P. Henklein, D. E. Ott, G. Holland, N. Bannert and U. Schubert, "Highly Conserved Serine Residue 40 in HIV-1 p6 Regulates Capsid Processing and Virus Core Assembly," Retrovirology, Vol. 8, 2011, p. 11. doi:10.1186/1742-4690-8-11

[48] E. R. Weiss and H. Gottlinger, "The Role of Cellular Factors in Promoting HIV Budding," Journal of Molecular Biology, Vol. 410, No. 4, 2011, pp. 525-533. doi:10.1016/j.jmb.2011.04.055

[49] B. Strack, A. Calistri, S. Craig, E. Popova and H. G. Gottlinger, "AIP1/ALIX Is a Binding Partner for HIV-1 p6 and EIAV p9 Functioning in Virus Budding," Cell, Vol. 114, No. 6, 2003, pp. 689-699. doi:10.1016/S0092-8674(03)00653-6

[50] C. Lazert, N. Chazal, L. Briant, D. Gerlie and J. C. Cortay, "Refined Study of the Interaction between HIV-1 p6 Late Domain and ALIX," Retrovirology, Vol. 5, 2008, p. 39. doi:10.1186/1742-4690-5-39

[51] U. Schubert, D. E. Ott, E. N. Chertova, R. Welker, U. Tessmer, M. F. Princiotta, J. R. Bennink, H. G. Krausslich and J. W. Yewdell, "Proteasome Inhibition Interferes with Gag Polyprotein Processing, Release, and Maturation of HIV-1 and HIV-2," Proceedings of the $\mathrm{Na}$ tional Academy of Sciences USA, Vol. 97, No. 24, 2000, pp. 13057-13062. doi:10.1073/pnas.97.24.13057

[52] D. E. Ott, L. V. Coren, E. N. Chertova, T. D. Gagliardi, U. Schubert, "Ubiquitination of HIV-1 and MuLV Gag," Virology, Vol. 278, No. 1, 2000, pp. 111-121. doi:10.1006/viro.2000.0648

[53] S. J. Neil, T. Zang and P. D. Bieniasz, "Tetherin Inhibits Retrovirus Release and Is Antagonized by HIV-1 Vpu," Nature, Vol. 451, 2008, pp. 425-430. doi:10.1038/nature 06553

[54] N. Van Damme, D. Goff, C. Katsura, R. L. Jorgenson, R. Mitchell, M. C. Johnson, E. B. Stephens and J. Guatelli, "The Interferon-Induced Protein BST-2 Restricts HIV-1 Release and Is Downregulated from the Cell Surface by 
the Viral Vpu Protein," Cell Host Microbe, Vol. 3, No. 4, 2008, pp. 245-252. doi:10.1016/j.chom.2008.03.001

[55] M. Dube, B. B. Roy, P. Guiot-Guillain, J. Mercier, J. Binette, G. Leung and E. A. Cohen, "Suppression of Tetherin-Restricting Activity upon Human Immunodeficiency Virus Type 1 Particle Release Correlates with Localization of $\mathrm{Vpu}$ in the Trans-Golgi Network," Journal of Virology, Vol. 83, No. 9, 2009, pp. 4574-4590. doi:10.1128/JVI.01800-08

[56] J. C. Guatelli, "Interactions of Viral Protein U (Vpu) with Cellular Factors," Current Topics in Microbiology and Immunology, Vol. 339, 2009, pp. 27-45. doi:10.1007/978-3-642-02175-6 2

[57] N. Jouvenet, S. J. Neil, C. Bess, M. C. Johnson, C. A. Virgen, S. M. Simon and P. D. Bieniasz, "Plasma Membrane Is the Site of Productive HIV-1 Particle Assembly," PLoS Biology, Vol. 4, No. 12, 2006, p. e435.

[58] V. Blot, F. Perugi, B. Gay, M. C. Prevost, L. Briant, F. Tangy, H. Abriel, O. Staub, M. C. Dokhelar and C. Pique, "Nedd4.1-Mediated Ubiquitination and Subsequent Recruitment of Tsg101 Ensure HTLV-1 Gag Trafficking towards the Multivesicular Body Pathway Prior to Virus Budding," Journal of Cell Science, Vol. 117, 2004, pp. 2357-2367. doi:10.1242/jcs.01095

[59] N. Chazal and D. Gerlier, "Virus Entry, Assembly, Budding, and Membrane Rafts," Microbiology and Molecular Biology Reviews, Vol. 67, No. 2, 2003, pp. 226-237. doi:10.1128/MMBR.67.2.226-237.2003

[60] B. Brugger, B. Glass, P. Haberkant, I. Leibrecht, F. T. Wieland and H. G. Krausslich, "The HIV Lipidome: A Raft with an Unusual Composition," Proceedings of the National Academy of Sciences USA, Vol. 103, No. 8, 2006, pp. 2641-2646. doi:10.1073/pnas.0511136103

[61] E. Chertova, O. Chertov, L. V. Coren, J. D. Roser, C. M. Trubey, J. W. Bess Jr., R. C. Sowder, 2nd, E. Barsov, B. L. Hood, R. J. Fisher, K. Nagashima, T. P. Conrads, T. D. Veenstra, J. D. Lifson and D. E. Ott, "Proteomic and Biochemical Analysis of Purified Human Immunodeficiency Virus Type 1 Produced from Infected Monocyte-Derived Macrophages," Journal of Virology, Vol. 80, No. 18, 2006, pp. 9039-9052. doi:10.1128/JVI.01013-06

[62] M. Bryant and L. Ratner, "Myristoylation-Dependent Replication and Assembly of Human Immunodeficiency Virus 1," Proceedings of the National Academy of Sciences USA, Vol. 87, No. 2, 1990, pp. 523-527. doi:10.1073/pnas.87.2.523

[63] W. Zhou, L. J. Parent, J. W. Wills and M. D. Resh, "Identification of a Membrane-Binding Domain within the Amino-Terminal Region of Human Immunodeficiency Virus Type 1 Gag Protein Which Interacts with Acidic Phospholipids," Journal of Virology, Vol. 68, 1994, pp. 2556-2569.

[64] E. O. Freed, "HIV-1 Gag: Flipped Out for PI(4,5)P(2)," Proceedings of the National Academy of Sciences USA, Vol. 103, No. 30, 2006, pp. 11101-11102. doi: $10.1073 /$ pnas. 0604715103
[65] J. S. Saad, J. Miller, J. Tai, A. Kim, R. H. Ghanam and M. F. Summers, "Structural Basis for Targeting HIV-1 Gag Proteins to the Plasma Membrane for Virus Assembly," Proceedings of the National Academy of Sciences USA, Vol. 103, No. 30, 2006, pp. 11364-11369. doi: $10.1073 /$ pnas.0602818103

[66] L. Hermida-Matsumoto and M. D. Resh, "Human Immunodeficiency Virus Type 1 Protease Triggers a Myristoyl Switch That Modulates Membrane Binding of Pr55 (Gag) and p17MA," Journal of Virology, Vol. 73, 1999, pp. 1902-1908.

[67] M. H. Naghavi and S. P. Goff, "Retroviral Proteins That Interact with the Host Cell Cytoskeleton," Current Opinion in Immunology, Vol. 19, No. 4, 2007, pp. 402-407. doi:10.1016/j.coi.2007.07.003

[68] Y. Tomita, T. Noda, K. Fujii, T. Watanabe, Y. Morikawa and Y. Kawaoka, "The Cellular Factors Vps18 and Mon2 Are Required for Efficient Production of Infectious HIV-1 Particles," Journal of Virology, Vol. 85, No. 11, 2011, pp. 5618-5627. doi:10.1128/JVI.00846-10

[69] X. Dong, H. Li, A. Derdowski, L. Ding, A. Burnett, X. Chen, T. R. Peters, T. S. Dermody, E. Woodruff, J. J. Wang and P. Spearman, "AP-3 Directs the Intracellular Trafficking of HIV-1 Gag and Plays a Key Role in Particle Assembly," Cell, Vol. 120, No. 5, 2005, pp. 663-674. doi:10.1016/j.cell.2004.12.023

[70] G. Camus, C. Segura-Morales, D. Molle, S. LopezVerges, C. Begon-Pescia, C. Cazevieille, P. Schu, E. Bertrand, C. Berlioz-Torrent and E. Basyuk, "The Clathrin Adaptor Complex AP-1 Binds HIV-1 and MLV Gag and Facilitates Their Budding," Molecular Biology of the Cell, Vol. 18, No. 8, 2007, pp. 3193-3203. doi:10.1091/mbc.E06-12-1147

[71] L. J. Parent, "New Insights into the Nuclear Localization of Retroviral Gag Proteins," Nucleus, Vol. 2, No. 2, 2011, pp. 92-97. doi:10.4161/nucl.2.2.15018

[72] S. Dupont, N. Sharova, C. DeHoratius, C. M. Virbasius, X. Zhu, A. G. Bukrinskaya, M. Stevenson and M. R. Green, "A Novel Nuclear Export Activity in HIV-1 Matrix Protein Required for Viral Replication," Nature, Vol. 402, 1999, pp. 681-685. doi:10.1038/45272

[73] N. Jouvenet, P. D. Bieniasz and S. M. Simon, "Imaging the Biogenesis of Individual HIV-1 Virions in Live Cells," Nature, Vol. 454, 2008, pp. 236-240. doi:10.1038/nature06998

[74] S. C. Pettit, N. Sheng, R. Tritch, S. Erickson-Viitanen and R. Swanstrom, "The Regulation of sequential Processing of HIV-1 Gag by the Viral Protease," Advances in Experimental Medicine and Biology, Vol. 436, 1998, pp. 15-25. doi:10.1007/978-1-4615-5373-1 2

[75] O. Pornillos, B. K. Ganser-Pornillos, B. N. Kelly, Y. Hua, F. G. Whitby, C. D. Stout, W. I. Sundquist, C. P. Hill and M. Yeager, "X-Ray Structures of the Hexameric Building Block of the HIV Capsid," Cell, Vol. 137, No. 7, 2009, pp. 1282-1292. doi:10.1016/j.cell.2009.04.063

[76] J. R. Cortines, E. B. Monroe, S. Kang and P. E. Prevelige Jr., "A Retroviral Chimeric Capsid Protein Reveals the 
Role of the N-Terminal beta-Hairpin in Mature Core Assembly," Journal of Molecular Biology, Vol. 410, No. 4, 2011, pp. 641-652. doi:10.1016/j.jmb.2011.03.052

[77] J. C. Paillart, M. Shehu-Xhilaga, R. Marquet and J. Mak, "Dimerization of Retroviral RNA Genomes: An Inseparable Pair," Nature Reviews Microbiology, Vol. 2, 2004, pp. 461-472. doi:10.1038/nrmicro903

[78] T. Murakami, S. Ablan, E. O. Freed and Y. Tanaka, "Regulation of Human Immunodeficiency Virus Type 1 Env-Mediated Membrane Fusion by Viral Protease Activity," Journal of Virology, Vol. 78, No. 2, 2004, pp. 1026-1031. doi:10.1128/JVI.78.2.1026-1031.2004

[79] D. J. Wyma, J. Jiang, J. Shi, J. Zhou, J. E. Lineberger, M. D. Miller and C. Aiken, "Coupling of Human Immunodeficiency Virus Type 1 Fusion to Virion Maturation: A Novel Role of the gp41 Cytoplasmic Tail," Journal of Virology, Vol. 78, No. 7, 2004, pp. 3429-3435. doi:10.1128/JVI.78.7.3429-3435.2004

[80] J. Sticht, M. Humbert, S. Findlow, J. Bodem, B. Muller, U. Dietrich, J. Werner and H. G. Krausslich, "A Peptide Inhibitor of HIV-1 Assembly in Vitro," Nature Structural \& Molecular Biology, Vol. 12, 2005, pp. 671-677. doi:10.1038/nsmb964

[81] F. Ternois, J. Sticht, S. Duquerroy, H. G. Krausslich and F. A. Rey, "The HIV-1 Capsid Protein C-Terminal Domain in Complex with a Virus Assembly Inhibitor," $\mathrm{Na}$ ture Structural \& Molecular Biology, Vol. 12, 2005, pp. 678-682. doi:10.1038/nsmb967

[82] H. Zhang, Q. Zhao, S. Bhattacharya, A. A. Waheed, X. Tong, A. Hong, S. Heck, F. Curreli, M. Goger, D. Cowburn, E. O. Freed and A. K. Debnath, "A Cell-Penetrating Helical Peptide as a Potential HIV-1 Inhibitor," Journal of Molecular Biology, Vol. 378, No. 3, 2008, pp. 565-580. doi:10.1016/j.jmb.2008.02.066

[83] C. S. Adamson and E. O. Freed, "Novel Approaches to Inhibiting HIV-1 Replication," Antiviral Research, Vol. 85 , No. 1, 2010, pp. 119-141. doi:10.1016/j.antiviral.2009.09.009

[84] F. Curreli, H. Zhang, X. Zhang, I. Pyatkin, Z. Victor, A. Altieri and A. K. Debnath, "Virtual Screening Based Identification of Novel Small-Molecule Inhibitors Targeted to the HIV-1 Capsid," Bioorganic \& Medicinal Chemistry, Vol. 19, No. 1, 2011, pp. 77-90. doi:10.1016/j.bmc.2010.11.045

[85] C. Tang, E. Loeliger, I. Kinde, S. Kyere, K. Mayo, E. Barklis, Y. Sun, M. Huang and M. F. Summers, "Antiviral Inhibition of the HIV-1 Capsid Protein," Journal of Molecular Biology, Vol. 327, No. 5, 2003, pp. 1013-1020. doi:10.1016/S0022-2836(03)00289-4

[86] B. N. Kelly, S. Kyere, I. Kinde, C. Tang, B. R. Howard, H. Robinson, W. I. Sundquist, M. F. Summers and C. P. Hill, "Structure of the Antiviral Assembly Inhibitor CAP-1 Complex with the HIV-1 CA Protein," Journal of Molecular Biology, Vol. 373, No. 2, 2007, pp. 355-366. doi:10.1016/j.jmb.2007.07.070

[87] J. Shi, J. Zhou, V. B. Shah, C. Aiken and K. Whitby, "Small-Molecule Inhibition of Human Immunodeficiency
Virus Type 1 Infection by Virus Capsid Destabilization," Journal of Virology, Vol. 85, 2011, pp. 542-549.

[88] E. O. Freed, "HIV-1 and the Host Cell: An Intimate Association," Trends in Microbiology, Vol. 12, No. 4, 2004, pp. 170-177. doi:10.1016/j.tim.2004.02.001

[89] U. M. Munshi, J. Kim, K. Nagashima, J. H. Hurley and E. O. Freed, "An Alix Fragment Potently Inhibits HIV-1 Budding: Characterization of Binding to Retroviral YPXL Late Domains," Journal of Biological Chemistry, Vol. 282, 2007, pp. 3847-3855. doi:10.1074/jbc.M607489200

[90] O. Pornillos, S. L. Alam, D. R. Davis and W. I. Sundquist, "Structure of the Tsg101 UEV Domain in Complex with the PTAP Motif of the HIV-1 p6 Protein," Nature Structural Biology, Vol. 9, 2002, pp. 812-817.

[91] F. Liu, A. G. Stephen, A. A. Waheed, M. J. Aman, E. O. Freed, R. J. Fisher and T. R. Burke Jr., "SAR by OximeContaining Peptide Libraries: Application to Tsg101 Ligand Optimization," ChemBioChem, Vol. 9, No. 12, 2008, pp. 2000-2004. doi:10.1002/cbic.200800281

[92] A. Tavassoli, Q. Lu, J. Gam, H. Pan, S. J. Benkovic and S. N. Cohen, "Inhibition of HIV Budding by a Genetically Selected Cyclic Peptide Targeting the Gag-TSG101 Interaction," ACS Chemical Biology, Vol. 3, No. 12, 2008, pp. 757-764. doi:10.1021/cb800193n

[93] T. Fujioka, Y. Kashiwada, R. E. Kilkuskie, L. M. Cosentino, L. M. Ballas, J. B. Jiang, W. P. Janzen, I. S. Chen and K. H. Lee, "Anti-AIDS Agents, 11. Betulinic Acid and Platanic Acid as Anti-HIV Principles from Syzigium Claviflorum, and the Anti-HIV Activity of Structurally Related Triterpenoids," Journal of Natural Products, Vol. 57, No. 2, 1994, pp. 243-247. doi: $10.1021 / \mathrm{np} 50104 \mathrm{a} 008$

[94] Y. Kashiwada, F. Hashimoto, L. M. Cosentino, C. H. Chen, P. E. Garrett and K. H. Lee, "Betulinic Acid and Dihydrobetulinic Acid Derivatives as Potent Anti-HIV Agents," Journal of Medicinal Chemistry, Vol. 39, No. 5, 1996, pp. 1016-1017. doi:10.1021/jm950922q

[95] F. Li, R. Goila-Gaur, K. Salzwedel, N. R. Kilgore, M. Reddick, C. Matallana, A. Castillo, D. Zoumplis, D. E. Martin, J. M. Orenstein, G. P. Allaway, E. O. Freed and C. T. Wild, "PA-457: A Potent HIV Inhibitor That Disrupts Core Condensation by Targeting a Late Step in Gag Processing," Proceedings of the National Academy of Sciences USA, Vol. 100, No. 23, 2003, pp. 13555-13560. doi:10.1073/pnas.2234683100

[96] I. C. Sun, C. H. Chen, Y. Kashiwada, J. H. Wu, H. K. Wang and K. H. Lee, "Anti-AIDS Agents 49. Synthesis, Anti-HIV, and Anti-Fusion Activities of IC9564 Analogues Based on Betulinic Acid," Journal of Medicinal Chemistry, Vol. 45, No. 19, 2002, pp. 4271-4275. doi: $10.1021 / \mathrm{jm} 020069 \mathrm{c}$

[97] L. Quere, T. Wenger and H. J. Schramm, "Triterpenes as Potential Dimerization Inhibitors of HIV-1 Protease," Biochemical and Biophysical Research Communications, Vol. 227, No. 2, 1996, pp. 484-488. doi:10.1006/bbrc. 1996.1533 
[98] J. F. Mayaux, A. Bousseau, R. Pauwels, T. Huet, Y. Henin, N. Dereu, M. Evers, F. Soler, C. Poujade, E. De Clercq, et al., "Triterpene Derivatives That Block Entry of Human Immunodeficiency Virus Type 1 into Cells," Proceedings of the National Academy of Sciences USA, Vol. 91, No. 9, 1994, pp. 3564-3568. doi:10.1073/pnas.91.9.3564

[99] B. Labrosse, O. Pleskoff, N. Sol, C. Jones, Y. Henin and M. Alizon, "Resistance to a Drug Blocking Human Immunodeficiency Virus Type 1 Entry (RPR103611) Is Conferred by Mutations in gp41," Journal of Virology, Vol. 71, 1997, pp. 8230-8236.

[100] X. Yuan, L. Huang, P. Ho, C. Labranche and C. H. Chen, "Conformation of gp120 Determines the Sensitivity of HIV-1 DH012 to the Entry Inhibitor IC9564," Virology, Vol. 324, No. 2, 2004, pp. 525-530. doi:10.1016/j.virol.2004.04.009

[101] S. Bar and M. Alizon, "Role of the Ectodomain of the gp41 Transmembrane Envelope Protein of Human Immunodeficiency Virus Type 1 in Late Steps of the Membrane Fusion Process," Journal of Virology, Vol. 78, No. 2, 2004, pp. 811-820. doi:10.1128/JVI.78.2.811-820.2004

[102] J. Zhou, X. Yuan, D. Dismuke, B. M. Forshey, C. Lundquist, K. H. Lee, C. Aiken and C. H. Chen, "Small- Molecule Inhibition of Human Immunodeficiency Virus Type 1 Replication by Specific Targeting of the Final Step of Virion Maturation," Journal of Virology, Vol. 78, 2004, pp. 922-929. doi:10.1128/JVI.78.2.922-929.2004

[103] P. W. Keller, C. S. Adamson, J. B. Heymann, E. O. Freed and A. C. Steven, "HIV-1 Maturation Inhibitor Bevirimat Stabilizes the Immature Gag Lattice," Journal of Virology, Vol. 85, 2011, pp. 1420-1428. doi:10.1128/JVI.01926-10

[104] B. Muller, M. Anders, H. Akiyama, S. Welsch, B. Glass, K. Nikovics, F. Clavel, H. M. Tervo, O. T. Keppler and H. G. Krausslich, "HIV-1 Gag Processing Intermediates Trans-Dominantly Interfere with HIV-1 Infectivity," Journal of Biological Chemistry, Vol. 284, 2009, pp. 2969229703. doi:10.1074/jbc.M109.027144

[105] J. Zhou, C. H. Chen and C. Aiken, "The Sequence of the CA-SP1 Junction Accounts for the Differential Sensitivity of HIV-1 and SIV to the Small Molecule Maturation Inhibitor 3-O-\{3',3'-Dimethylsuccinyl $\}$-betulinic Acid," Retrovirology, Vol. 1, 2004, p. 15. doi:10.1186/1742-4690-1-15

[106] S. DaFonseca, A. Blommaert, P. Coric, S. S. Hong, S. Bouaziz and P. Boulanger, "The 3-O-(3',3'-Dimethylsuccinyl) Derivative of Betulinic Acid (DSB) Inhibits the Assembly of Virus-Like Particles in HIV-1 Gag Precursor-Expressing Cells," Antiviral Therapy, Vol. 12, 2007, pp. 1185-1203.

[107] J. Zhou, L. Huang, D. L. Hachey, C. H. Chen and C. Aiken, "Inhibition of HIV-1 Maturation Via Drug Association with the Viral Gag Protein in Immature HIV-1 Particles," Journal of Biological Chemistry, Vol. 280, 2005, pp. 42149-42155. doi:10.1074/jbc.M508951200

[108] D. E. Martin, R. Blum, J. Wilton, J. Doto, H. Galbraith, G. L. Burgess, P. C. Smith and C. Ballow, "Safety and
Pharmacokinetics of Bevirimat (PA-457), a Novel Inhibitor of Human Immunodeficiency Virus Maturation, in Healthy Volunteers," Antimicrobial Agents and Chemotherapy, Vol. 51, No. 9, 2007, pp. 3063-3066. doi:10.1128/AAC.01391-06

[109] C. S. Adamson, S. D. Ablan, I. Boeras, R. Goila-Gaur, F. Soheilian, K. Nagashima, F. Li, K. Salzwedel, M. Sakalian, C. T. Wild and E. O. Freed, "In Vitro Resistance to the Human Immunodeficiency Virus Type 1 Maturation Inhibitor PA-457 (Bevirimat)," Journal of Virology, Vol. 80, No. 22, 2006, pp. 10957-10971. doi:10.1128/JVI.01369-06

[110] K. Van Baelen, K. Salzwedel, E. Rondelez, V. Van Eygen, S. De Vos, A. Verheyen, K. Steegen, Y. Verlinden, G. P. Allaway and L. J. Stuyver, "Susceptibility of Human Immunodeficiency Virus Type 1 to the Maturation Inhibitor Bevirimat Is Modulated by Baseline Polymorphisms in Gag Spacer Peptide 1," Antimicrobial Agents and Chemotherapy, Vol. 53, 2009, pp. 2185-2188. doi:10.1128/AAC.01650-08

[111] P. F. Smith, A. Ogundele, A. Forrest, J. Wilton, K. Salzwedel, J. Doto, G. P. Allaway and D. E. Martin, "Phase I and II Study of the Safety, Virologic Effect, and Pharmacokinetics/Pharmacodynamics of Single-Dose 3O-(3',3'-Dimethylsuccinyl)betulinic acid (Bevirimat) against Human Immunodeficiency Virus Infection," Antimicrobial Agents and Chemotherapy, Vol. 51, No. 10, 2007, pp. 3574-3581. doi:10.1128/AAC.00152-07

[112] N. A. Margot, C. S. Gibbs and M. D. Miller, "Phenotypic Susceptibility to Bevirimat in Isolates from HIV-1-Infected Patients without Prior Exposure to Bevirimat," Antimicrobial Agents and Chemotherapy, Vol. 54, No. 6, 2010, pp. 2345-2353. doi:10.1128/AAC.01784-09

[113] R. M. McAllister, J. Lalezari, G. Richmond, M. Thompson, R. Harrigan, D. Martin, K. Salzwedel and D. Allaway, "HIV-1 Gag Polymorphisms Determine Treatment Response to Bevirimat (PA-457)," Antiviral Therapy, Vol. 13, 2008, pp. A10.

[114] W. Lu, K. Salzwedel, D. Wang, S. Chakravarty, E. O. Freed, C. T. Wild and F. Li, "A Single Polymorphism in HIV-1 Subtype C SP1 Is Sufficient to Confer Natural Resistance to the Maturation Inhibitor, Bevirimat," Antimicrobial Agents and Chemotherapy, Vol. 55, No. 7, 2011, pp. 3324-3329.

[115] J. Cao, J. Isaacson, A. K. Patick and W. S. Blair, "HighThroughput Human Immunodeficiency Virus Type 1 (HIV-1) Full Replication Assay That Includes HIV-1 Vif as an Antiviral Target," Antimicrobial Agents and Chemotherapy, Vol. 49, No. 9, 2005, pp. 3833-3841. doi:10.1128/AAC.49.9.3833-3841.2005

[116] W. S. Blair, J. Cao, J. Fok-Seang, P. Griffin, J. Isaacson, R. L. Jackson, E. Murray, A. K. Patick, Q. Peng, M. Perros, C. Pickford, H. Wu and S. L. Butler, "New SmallMolecule Inhibitor Class Targeting Human Immunodeficiency Virus Type 1 Virion Maturation," Antimicrobial Agents and Chemotherapy, Vol. 53, No. 12, 2009, pp. 5080-5087. doi:10.1128/AAC.00759-09

[117] L. Huang, P. Ho, K. H. Lee and C. H. Chen, "Synthesis 
and Anti-HIV Activity of Bi-Functional Betulinic Acid Derivatives," Bioorganic \& Medicinal Chemistry, Vol. 14, No. 7, 2006, pp. 2279-2289. doi:10.1016/j.bmc.2005.11.016

[118] Z. Dang, W. Lai, K. Qian, P. Ho, K. H. Lee, C. H. Chen and L. Huang, "Betulinic Acid Derivatives as Human Immunodeficiency Virus Type 2 (HIV-2) Inhibitors," Journal of Medicinal Chemistry, Vol. 52, No. 23, 2009, pp. 7887-7891. doi:10.1021/jm9004253

[119] I. Huvent, S. S. Hong, C. Fournier, B. Gay, J. Tournier, C. Carriere, M. Courcoul, R. Vigne, B. Spire and P. Bou- langer, "Interaction and Co-Encapsidation of Human Immunodeficiency Virus Type 1 Gag and Vif Recombinant Proteins," Journal of General Virology, Vol. 79, 1998, pp. 1069-1081.

[120] N. Morellet, S. Druillennec, C. Lenoir, S. Bouaziz and B. P. Roques, "Helical Structure Determined by NMR of the HIV-1 (345-392)Gag Sequence, Surrounding p2: Implications for Particle Assembly and RNA Packaging," Protein Science, Vol. 14, No. 2, 2005, pp. 375-386. doi: $10.1110 /$ ps.041087605 